\title{
Does informal learning at work differ between temporary and permanent workers? Evidence from 20 OECD countries
}

Citation for published version (APA):

Ferreira Sequeda, M., de Grip, A., \& van der Velden, R. (2018). Does informal learning at work differ between temporary and permanent workers? Evidence from 20 OECD countries. Labour Economics, 55, 18-40. https://doi.org/10.1016/j.labeco.2018.08.009

Document status and date:

Published: 01/12/2018

DOI:

10.1016/j.labeco.2018.08.009

Document Version:

Publisher's PDF, also known as Version of record

Document license:

Taverne

Please check the document version of this publication:

- A submitted manuscript is the version of the article upon submission and before peer-review. There can be important differences between the submitted version and the official published version of record.

People interested in the research are advised to contact the author for the final version of the publication, or visit the DOI to the publisher's website.

- The final author version and the galley proof are versions of the publication after peer review.

- The final published version features the final layout of the paper including the volume, issue and page numbers.

Link to publication

\footnotetext{
General rights rights.

- You may freely distribute the URL identifying the publication in the public portal. please follow below link for the End User Agreement:

www.umlib.nl/taverne-license

Take down policy

If you believe that this document breaches copyright please contact us at:

repository@maastrichtuniversity.nl

providing details and we will investigate your claim.
}

Copyright and moral rights for the publications made accessible in the public portal are retained by the authors and/or other copyright owners and it is a condition of accessing publications that users recognise and abide by the legal requirements associated with these

- Users may download and print one copy of any publication from the public portal for the purpose of private study or research.

- You may not further distribute the material or use it for any profit-making activity or commercial gain

If the publication is distributed under the terms of Article $25 \mathrm{fa}$ of the Dutch Copyright Act, indicated by the "Taverne" license above, 


\title{
Does informal learning at work differ between temporary and permanent workers? Evidence from 20 OECD countries ${ }^{\text {th }}$
}

\author{
Maria Ferreira $^{\mathrm{a}, \mathrm{b}}$, Andries de Grip ${ }^{\mathrm{a}, \mathrm{c}, *}$, Rolf van der Velden ${ }^{\mathrm{a}}$ \\ a School of Business and Economics, Maastricht University, The Netherlands \\ ${ }^{\mathrm{b}}$ School of Business and Economics, Industrial University of Santander, Colombia \\ ${ }^{\mathrm{c}}$ IZA, Germany
}

\section{A R T I C L E I N F O}

JEL classifications:

E24

$\mathrm{J} 24$

$\mathrm{J} 41$

\section{Keywords:}

Temporary contracts

Informal learning

Training

Human capital investments

\begin{abstract}
A B S T R A C T
This paper analyses the relationship between temporary employment and the intensity of on-the-job informal learning across 20 developed countries. Using microdata from the OECD's PIAAC survey, we estimate an instrumented endogenous switching regression model and find that temporary employees engage in on-the-job learning more intensively than their counterparts in permanent employment. We show that this higher intensity of informal learning does not substitute for temporary workers' lower participation in formal training. Instead, both types of learning are complementary. Heterogeneous-effect analyses suggests that early career expectations of gaining a permanent contract could explain the higher informal learning investments of employees while in a temporary job.
\end{abstract}

\section{Introduction}

During the last two decades, temporary employment has increased substantially in many OECD countries (OECD, 2014). Ideally, on-thejob investments in human capital (i.e. training and learning from experience) in this type of jobs should improve the integration of new entrants or unemployed individuals into the labour market. However, both in public policy and in the economic literature, there is a debate about the opportunities for human capital development associated with temporary contracts (Arulampalam and Booth, 1998; Booth et al., 2002; OECD, 2014).

Despite the debate and policy relevance, remarkably little is known about the difference between temporary and permanent employees with respect to the learning content of their jobs. Mainly due to the lack of appropriate data, the empirical literature has thus far been entirely focused on workers' training participation. In line with human capital theory, several empirical studies have provided evidence of a negative relation between temporary contracts and training participation in various countries (e.g. Arulampalam et al., 2004; Cutulli and Guetto, 2013). The empirical question on whether and, if so, to what extend learning informally on the job differs between temporary and permanent employees still remains.

Policy makers in most OECD countries have become increasingly aware that informal learning over the working life represents also a rich source of human capital and skills development, usually recognised through the experience wage premium in the labour market (OECD, 2010, 2013a). Although years of experience (or tenure) have played an important role in the economic literature as a proxy for unobservable investments in learning while working (Mincer, 1974), there are hardly any empirical studies on the learning potential of different jobs or the extent to which different workers learn from experience (Rosen, 1972; Tesluk and Jacobs, 1998; Heckman et al., 2002).

In this article, we contribute to filling this gap by providing empirical evidence on the influence of temporary contracts on the intensity of informal learning at work across 20 OECD countries. ${ }^{1}$ For our analysis, we use unique data from the OECD Programme for International

\footnotetext{
1 Table 1 shows the countries included in our analyses.
}

\footnotetext{
औ We gratefully acknowledge comments from Lex Borghans, Bart Cockx, Denis de Crombrugghe, Thomas Dohmen, Bart Golsteyn, Colin Green, Olivier Marie, Raymond Montizaan, Kjell Salvanes, Ludger Woessmann, Jeffrey Wooldridge, and participants of the LEER Workshop on Education Economics (2015), the DUHR Seminar Maastricht (2015), the IEB Workshop on Education Economics (2016), the ROA Human Capital conference (2016) and the conferences of the European Society for Population Economics (2015), the International Association for Applied Econometrics (2015), and European Association of Labour Economics (2016, 2017). We also thank three anonymous referees and a co-editor of this journal for all their insightful comments and suggestions.

* Corresponding author at: Maastricht University, School of Business and Economics, P.O. Box 616, Maastricht, MD 6200, The Netherlands.

E-mail addresses: m.ferreirasequeda@maastrichtuniversity.nl (M. Ferreira), a.degrip@maastrichtuniversity.nl (A. de Grip), r.vandervelden@maastrichtuniversity.nl (R.van der Velden).
} 
Assessment of Adult Competences (PIAAC) survey conducted in 2011 and 2012. This is the first survey that provides detailed internationally comparable measures of workers' skills, job-tasks content and informal learning at work, the latter based on a conceptual framework that considers three modes of informal learning: (1) learning by doing, (2) learning from others, and (3) learning by keeping up-to-date with new products or services.

We contribute to the literature on flexible employment and human capital development in three ways. First, we estimate the extent to which the intensity of informal learning on the job differs between workers with temporary and permanent contracts. In doing so, we raise the issue of potential endogeneity of enrolment in a temporary job due to selection based on unobservable characteristics. We not only include several important and previously neglected control variables in the temporary contracts literature (such as workers' skills, learning attitude and taskjob content) but also implement an endogenous switching regression model (SRM) to correct for the expected negative bias in a naïve ordinary least squares (OLS) estimation. To this end, we exploit the differential exposure of workers of different ages to employment protection legislation (EPL) and potential unemployment, using age-group-by-country information six years prior to the data generation. ${ }^{2}$ We obtain consistent estimates by applying the full-information maximum likelihood (FIML) method and show our estimations to be robust. Our main results show that workers in temporary jobs invest more intensively in informal learning than their counterparts in permanent contracts do, although the former are, in line with the empirical human capital literature, less likely, on average, to participate in formal training activities.

Second, we explore the interaction between training and informal learning to analyse whether there is substitution or complementarity between these two types of learning for both temporary and permanent employees. We find evidence of a complementarity relation, regardless of the type of contract, which suggests that the higher informal learning investments of temporary workers do not substitute for the lack of formal training.

Third, we provide marginal treatment effects (MTEs) estimates to analyse the heterogeneity in workers' informal learning along the distribution of their individual unobserved characteristics. This analysis shows whether informal learning outcomes for workers on the margin of a temporary job placement change with the probability of selection into a temporary contract by marginally increasing the corresponding interaction between the unemployment rate and EPL measures we use as selection instruments in our identification strategy. Allowing for this type of heterogeneity reinforces our main finding: There is a consistent difference in on-the-job informal learning between temporary and permanent employees in favour of those who have a temporary contract. Interestingly, this difference is expected to be larger among workers with lower propensities of selection into temporary jobs, that is, those who are likely to have better unobservable characteristics (e.g. ability and motivation).

We also provide additional insights on the possible mechanisms that could explain our main result. To that aim, we perform several heterogeneous-effect analyses taking into consideration different observable individual and job-task content characteristics. In evaluating this heterogeneity, the most important concern is the possibility that firms select workers into temporary contracts due to the different task content of jobs and/or workers' different levels of skills beyond their educational level. This could lead to unobservable differences in learning opportunities by contract type. This kind of problem has been

\footnotetext{
2 We use male unemployment rates by country as a selection instrument, which vary within countries across five-year age groups. We collected these unemployment data from six years preceding the respondent's interview date to ensure that, first, the current (in sample) and past (in instrument) five-year age groups refer to the same age group but not to the same cohort of individuals and, second, that we use consistent unemployment information prior to the occurrence of the global financial crisis for all employees in our sample.
}

largely overlooked in the literature on flexible employment. We find that employees with higher levels of numeracy/literacy skills are indeed less likely to have temporary contracts. We also find that workers with jobs that involve tasks of greater skills demand and flexibility have a lower probability of being selected into temporary contracts and are simultaneously more intensively engaged in informal learning. Furthermore, we find some heterogeneity with respect to workers' age and tenure.

Although the PIAAC data do not allow us to identify the particular mechanism driving our main finding, we discuss some heterogeneouseffect analyses in light of the theoretical idea that expectations of transition to permanent employment could be responsible for the stronger incentives to invest in informal learning while in a temporary job. Additional results from a different cross-country dataset at the European level provide descriptive support for this hypothesis.

The remainder of the paper is organised as follows. Section 2 discusses the literature related to our research question. Section 3 presents our model and empirical strategy and discusses the plausibility of the identifying assumptions. Section 4 describes our data. Section 5 presents our main empirical results, and robustness and heterogeneity analyses. Section 6 concludes the paper and discusses its main findings and implications.

\section{Related literature}

Studying how temporary contracts influence decisions of investment in informal learning at work in comparison to permanent contracts relates to two strands of economics research. First, the human capital literature on training investments and, second, the stepping-stone or deadend job effects of temporary contracts.

From a theoretical perspective, firms using temporary contracts to adjust the size of their labour force have fewer incentives to invest in the human capital of these employees because of the shorter expected amortisation period. Workers in this situation are also expected to invest less in the accumulation of firm-specific skills. If that is the case, then the pursuit of flexible production by firms could impose negative externalities not only on the skills development of their current flexible workforce but also on their long-term productive capacity due to suboptimal aggregate training investments (Arulampalam and Booth, 1998). Previous empirical studies have confirmed this negative relation between temporary work and training participation (Atkinson, 1998; Arulampalam et al., 2004; Steijn et al., 2006; O'Connell and Byrne, 2012; Cutulli and Guetto, 2013). Other studies have shown, however, that employers may invest in the general training of temporary employees due to the existence of labour market imperfections (Acemoglu and Pischke, 1999) or to screen workers according to ability prior to offering a permanent contract (Autor, 2001).

The latter reference leads us to the related literature on the steppingstone effects of temporary employment. Most research in this field has claimed that on-the-job learning (both training and informal learning) and skills development are probably the main channel through which temporary contracts can offer a path into permanent employment. The odds of transition to a permanent position are believed to increase with the improvement of human capital and the gain of productive experience while in a temporary job (Autor, 2001; Booth et al., 2002; Gagliarducci, 2005; De Graaf-Zijl et al., 2011; Cockx and Picchio, 2012; Jahn and Pozzoli, 2013; Jahn and Rosholm, 2014). This strand of literature suggests that temporary employment could provide workers with further incentives for investments in on-the-job learning to improve their skills (or offset the deterioration of their human capital while unemployed) and thereby increase their chances of finding a more stable job. Nonetheless, these studies have also noted that, if temporary jobs are recurrent, the stepping-stone prospects decrease and human capital investments are expected to decline. Temporary employment could then become dead-end jobs.

However, due to the lack of appropriate data, little has been done to validate that learning on the job could be an important mechanism 
to explain the transition probabilities from temporary to permanent employment. Although we do not aim to test for this mobility, we contribute to this literature by analysing the difference in the intensity of informal learning on the job between workers with temporary and permanent contracts, which has not yet been empirically analysed.

In this respect, our study relates to the literature on human capital accumulation, which has explained that, in addition to training participation, workers' human capital development over the life course is also affected by informal learning on the job. Mincer (1974) claims that onthe-job informal learning probably constitutes the major human capital investment in the workplace. In the human capital literature, informal learning has mainly been seen as learning-by-doing or learning through experience. Following the seminal work of Arrow (1962) and Mincer (1974), years of experience (or tenure) have been considered as a proxy for the unobservable investments in informal learning. However, simply accumulating years of experience assumes that, for any worker, each hour of work is equally effective in improving skills (Heckman et al., 2002). Quinones et al. (1995) and Tesluk and Jacobs (1998) show that this does not hold, while Maurer and Weiss (2010) show that not everyone is good at learning from experience. Furthermore, firms offer different levels of learning opportunities and jobs differ widely in their learning potential (Rosen, 1972; Heckman et al., 2002). ${ }^{3}$ More recent empirical studies have emphasised that workers are continuously learning by doing and learning from other workers and that such knowledge spill-over has a positive effect on their productivity (Destré et al., 2008; De Grip et al., 2016). In such settings, workers' human capital increases with tenure and converges towards the job's proficiency level and the firm's job-specific learning potential.

The literature on informal learning has some important implications for our study. First, it suggests that both the direct and indirect costs of investments in training are expected to be higher than those for informal learning since human capital accumulation and labour supply compete for employees' working time when investing in training, while they do not compete in case of learning-by-doing or learning from others (Heckman et al., 2002). Therefore, the analysis on the relation between training and temporary contracts could not be extended and generalised to informal learning. Second, years of experience and tenure are imperfect variables to provide information on informal learning on the job. Thus, the question whether the intensity of learning on the job differ - and, if so, to what extent - between employees with temporary and permanent contracts still remains.

\section{Model and empirical strategy}

Our primary regression equation of interest is

$\mathrm{IL}_{i}=\mathrm{X}_{i} \beta+\delta \mathrm{T}_{i}+\mu_{i}$

where IL is a continuous variable that measures the on-the-job informal learning intensity of worker $i, \mathrm{X}$ is a vector of covariates composed by worker and firm characteristics along with a set of country dummies, and $\mathrm{T}$ is a binary indicator of the type of contract $(\mathrm{T}=1$ for employees on temporary contracts and $\mathrm{T}=0$ for employees on permanent contracts). For this model, the difference in informal learning between workers with temporary and permanent contracts is measured by the estimate of $\delta$.

However, the binary indicator of the type of contract $\mathrm{T}_{i}$ cannot be treated as exogenous because it is potentially based on individual selfselection or selection by employers. Unobservable worker characteristics such as ability and motivation (Loh, 1994; Mincer, 1997; Autor, 2001; Givord and Wilner, 2015) as well as time preferences and risk

\footnotetext{
${ }^{3}$ The heterogeneity of informal learning experiences in the workplace has been mostly studied in the management and organisations literature. This heterogeneity depends on the extent to which the firm or job offers employees opportunities to undertake challenging tasks, interact with others, organise their own work, and so forth (Koopmans et al., 2006; De Grip, 2008; Marsick et al., 2009).
}

aversion (Weiss, 1986; Mincer, 1997; Belzil and Leonardi, 2007; Berton and Garibaldi, 2012) could affect both selection into a temporary job and investments in informal learning decision, resulting in biased estimates when using OLS. For instance, if the typical individual selected into temporary contracts has relatively lower ability or stronger time preferences for the present, then the OLS estimate of $\delta$ will underestimate the temporary contract effect. We might expect the bias to also be negative if employers tend to select temporary workers particularly for jobs of, for example, lower skill demand or lesser task complexity. If we feel these hypotheses are correct, then we would argue that $\delta$ underestimates the influence of temporary contracts on on-the-job informal learning.

We account for the endogeneity of temporary job selection by including several important and previously neglected control variables in the temporary contracts literature and estimating an endogenous switching regression model. Following Heckman (1978), Heckman and Vytlacil (1999), and Heckman et al. (2001), the more general model is the following. The potential informal learning outcomes $\left(\mathrm{IL}_{0}, \mathrm{IL}_{1}\right)$ of the type of contract $\mathrm{T}=\left(\begin{array}{ll}0 & 1\end{array}\right)$ are assumed to depend linearly upon observable variables $\mathrm{X}$ and unobservables $\mu_{i}$, as in Eq. (1). The temporary contract indicator is modelled as a nonlinear function of observables $Z_{i}$ and unobservables $v_{i}$ and is linked to the observed outcome $\mathrm{IL}_{i}$ through the latent variable $\mathrm{T}^{*}$ :

$$
\begin{aligned}
& \mathrm{T}_{i}^{*}=Z_{i} \gamma-v_{i} \\
& \mathrm{~T}_{i}= \begin{cases}1, & \text { if } \mathrm{T}_{i}^{*}>0 \\
0, & \text { if } \mathrm{T}_{i}^{*} \leq 0\end{cases} \\
& \operatorname{Prob}\left(T_{i}=1 \mid Z_{i}\right)=\Phi\left(Z_{i} \gamma\right) \\
& \operatorname{Prob}\left(T_{i}=0 \mid Z_{i}\right)=1-\Phi\left(Z_{i} \gamma\right)
\end{aligned}
$$

Consistent with our previous conjectures, the conditional independence assumption does not hold in these kinds of models. Instead, $\mu_{i}$ and $v_{i}$ are allowed to be correlated by a coefficient $\rho$ and assumed to be jointly normally distributed $\left(\mu_{i}, v_{i}\right) \sim N(0, \Sigma)$ (Maddala, 1983; Wooldridge, 2010; Greene, 2012). Under these assumptions, the bias caused by the correlation of the type of contract $\mathrm{T}$ with omitted variables is addressed by the nonzero expectation of the error term $\mu_{i}$ in Eq. (1), as follows:

$$
\begin{array}{r}
\mathrm{E}\left(\mathrm{IL}_{i} \mid T_{i}=1, \mathrm{X}_{i}, \mathrm{Z}_{i}\right)=\mathrm{X}_{i} \beta+\delta+\rho \sigma_{\mu}\left[\frac{\phi\left(-Z_{i} \gamma\right)}{\Phi\left(-Z_{i} \gamma\right)}\right] \\
\mathrm{E}\left(\mathrm{IL}_{i} \mid T_{i}=0, X_{i}, Z_{i}\right)=\mathrm{X}_{i} \beta+\rho \sigma_{\mu}\left[\frac{-\phi\left(-Z_{i} \gamma\right)}{1-\Phi\left(-Z_{i} \gamma\right)}\right]
\end{array}
$$

Then, the expected difference in informal learning between temporary and permanent employees is

$\mathrm{E}\left(\mathrm{IL}_{i} \mid T_{i}=1, X_{i}, \mathrm{Z}_{i}\right)-\mathrm{E}\left(\mathrm{IL}_{i} \mid T_{i}=0, \mathrm{X}_{i}, \mathrm{Z}_{i}\right)=\delta+\rho \sigma_{\mu}\left[\frac{\phi_{i}}{\Phi_{i}\left(1-\Phi_{i}\right)}\right]$

where $\phi_{i}=\phi\left(-Z_{i} \gamma\right)$ and $\Phi_{i}=\Phi\left(-Z_{i} \gamma\right)$, which are the standardised normal density and distribution functions respectively.

The model is identified through exclusion restrictions: first, including at least one instrumental variable in $Z$ that is excluded from the IL Eq. (1) and, second, the nonlinearity of the selection Eq. (2) that provides the temporary contract propensity score $p_{i}\left(\mathrm{Z}_{i}\right)$ and thus the correlation between $\mu_{i}$ and $v_{i}$. For the former, we exploit variation between and within countries in workers' differential exposure to potential unemployment by using the corresponding statistics on unemployment rate by country and age groups as measured six years prior to the survey. Identification thus first requires that the unemployment rate at the agegroup-by-country level induces variation in the probability of having a temporary contract, conditional on all the other covariates. This relation indeed exists in our application (see Section 4.2.4 and Panel B of 
Table 4). Second, the selection instrument (the unemployment rate at $t-6$ ) should be independent of the unobserved component in the IL Eq. (1) and should not directly affect the intensity of informal learning at work, conditional on the observed characteristics $X$. We establish the admissibility of our selection instrument in Sections 4 and 5.

To yield consistent and efficient estimates of the ATE, we apply the FIML method that simultaneously fit Eqs. (1) and (2) of our model by minimising the determinant of the covariance matrix associated with the residuals of the reduced form of the equation system.

Furthermore, by allowing $\beta_{0} \neq \beta_{1}$ and/or $\sigma_{0}^{2} \neq \sigma_{1}^{2}$ and $\rho_{0} \neq \rho_{1}$, where $\sigma^{2}$ represents the separate variance of $\mu_{i}$ in $\Sigma$ and $\rho$, or the separate correlation parameters for permanent and temporary workers, respectively, we can obtain the interacted endogenous SRM in which the impact of observed and/or unobserved characteristics is allowed to vary between workers with permanent and temporary contracts (Maddala, 1983; Heckman and Vytlacil, 2005; Wooldridge, 2010). Then, model (1) becomes

$$
\mathrm{IL}_{i}=X_{i} \beta_{0}+\delta \mathrm{T}_{i}+\mathrm{T}_{i}\left(\mathrm{X}_{i}-\overline{\mathrm{X}}\right) \beta_{1}+\mu_{i 0}+\mathrm{T}_{i}\left(\mu_{i 1}-\mu_{i 0}\right)
$$

Since the type of contract may create interaction effects with $X_{i}$ and $\mu_{i}$, heterogeneous effects of temporary employment on investments in informal learning on the job may result from both observed (differences between $X_{i} \beta_{0}$ and $X_{i} \beta_{1}$ ) and unobserved personal characteristics (differences between $\mu_{i 1}$ and $\mu_{i 0}$ ). This way of expressing the model emphasises our primary interest in $\delta$, although $\delta+\left(X_{i}-\overline{\mathrm{X}}\right) \beta_{1}$ is of interest for studying how the ATE changes as a function of observables, that is, to estimate nonconstant treatment effects and ATT (Wooldridge, 2010). The model also allows us to estimate treatment effect heterogeneity as a function of unobservables $U_{D}$ or MTEs (Quandt, 1972; Heckman and Vytlacil, 1999, 2001, 2005). This literature shows that the selection probability into temporary contracts given by Eq. (2), which is the propensity score $p_{i}\left(\mathrm{Z}_{i}\right)$, is a valid instrument, given selection on unobservables, and it can be used to identify MTEs. ${ }^{4}$ These are, in our case, the average treatment effects for workers on the margin of a temporary job placement, a margin that varies with the unemployment and EPL measures we use as instruments.

The endogenous SRM offers some advantages over the standard instrumental variable (IV) approach. ${ }^{5}$ First, the SRM adds more structure to account for the binary nature of our endogenous regressor. If the nonlinear model approximates the conditional expected function of the temporary contract selection better than a linear model, the outcome estimates of informal learning investments will be much more precise than the IV estimator (Angrist and Pischke, 2009; Wooldridge, 2010, 2015). Second, a continuous selection instrument is suitable for

\footnotetext{
4 The MTE is the marginal effect of a temporary contract $(T=1)$ on informal learning on the job, conditional on $\mathrm{X}$ and the unobservables $\mathrm{v}$ from the selection Eq. (2). In the MTE literature, it is customary to trace out the treatment effect against the percentiles of the distribution of $v$, in line with the following transformation of the selection rule in Eq. (2): $\mathrm{T}_{i}^{*}>0$ if $\Phi\left(Z_{i} \gamma\right)>\Phi\left(\mathrm{v}_{i}\right)$. Since $\Phi\left(Z_{i} \gamma\right)=p_{i}\left(Z_{i}\right)$ represents the selection probability into a temporary contract, $\Phi\left(v_{i}\right)=U_{D}$ denotes the percentiles of the distribution of the unobservable propensity of being selected into a permanent job. The condition $\mathrm{T}_{i}^{*}>0$ can then be rewritten as $U_{D}\left(\mathrm{Z}_{i}\right)>\mathrm{v}_{i}$. The MTE can then be estimated as the partial derivative of the conditional expectation of IL with respect to the propensity score $p_{i}\left(Z_{i}\right)$, as follows: $\operatorname{MTE}\left(X_{i}=\mathrm{x}, U_{D i}=p\right)=\partial E\left\{I L_{i} \mid X_{i}=\mathrm{x}, p_{i}\left(Z_{i}\right)=p\right\} / \partial p$. It is thus the treatment effect for individuals with observed characteristics $X_{i}=\mathrm{x}$ who are at the $U_{D}{ }^{\text {th }}$ percentile of the $v$ distribution, implying these individuals are indifferent between a permanent and a temporary contract when the propensity score $p_{i}\left(\mathrm{Z}_{i}\right)$ equals $U_{D}$.

${ }^{5}$ In the standard case of linear endogenous variables, both the SRM and 2SLS methods lead to the same estimator. When the treatment has a nonlinear effect on the outcome or the effect is heterogeneous, however, the methods produce different estimates. Imbens and Wooldridge (2009) conjecture that the SRM estimator is likely much more precise because it solves the nonlinear endogeneity by adding the scalar $\hat{v}$ to the regression while keeping the treatment variable in the second stage not only the linear projection as in 2SLS.
}

a binary endogenous regressor, which also facilitates the estimation of MTEs (Heckman and Vytlacil, 1999; Imbens and Wooldridge, 2009). Third, it easily adapts to handle more complicated models, such as heterogeneous-effect models. The IV approach can be quite inefficient relative to the more parsimonious SRM approach in this case. Thus, by allowing the estimation of heterogeneous effects, the SRM can be applied to estimate ATE as well as ATT and MTEs (Heckman and NavarroLozano, 2004; Angrist and Pischke, 2009; Wooldridge, 2010, 2015). Finally, in contrast to the SRM approach, 2SLS merely provides local ATEs instead of unconditional ATEs that are more policy relevant in the context of our research question.

However, this approach, while likely more efficient than an IV approach, is less robust. The consistency of the FIML estimator of the SRM hinges on the bivariate normality assumption of $\mu_{i}$ and $v_{i}$; thus, it is asymptotically efficient if the temporary contract selection Eq. (2) is correctly specified. The better the prediction of selection into a temporary job, the more precise the estimates of the informal learning outcome will be (Heckman, 1978; Heckman and Vytlacil, 2005; Wooldridge, 2010). Since the benefit of increased precision might be at the cost of a greater chance of misspecification error, we perform various robustness checks of our estimations.

\section{Data and descriptive statistics}

\subsection{Data and sample}

We use data from the OECD PIAAC survey, conducted in 2011 and 2012 , based on a representative sample of the population of the participant countries. ${ }^{6}$ This is a unique dataset that provides, for the first time, internationally comparable measures of informal learning at work, based on a conceptual framework that considers three learning pathways, namely, learning by doing, learning from others, and learning by keeping up-to-date with new products or services. Moreover, this dataset provides information on several worker, job, tasks and employer characteristics.

We restrict our sample to full-time male workers ${ }^{7}$ - excluding selfemployed and armed forces employees - aged 17 to 65, not participating in any formal education programme, and who have an employment contract that is not an apprenticeship or other training scheme. The sample consists of 25,853 observations ${ }^{8}$ for 20 OECD countries, ${ }^{9}$ with $88.2 \%$ permanent contracts and $11.8 \%$ temporary contracts. The distribution of permanent and temporary contracts in the sample is similar and

\footnotetext{
${ }^{6}$ See OECD (2014b) for further details about data validation.

7 We focus on males due to the higher probability of working career interruptions among women. Temporary jobs could differ in significance between men and women, since women might prefer career flexibility throughout a significant portion of their working lives (Booth et al., 2002).

8 In Canada, the sample consisted of 5,044 cases, from which we took a random sample of 1,193 cases to reduce bias due to oversampling of the Canadian respondents.

${ }^{9}$ Four countries were excluded from our sample: Australia, Cyprus, the Russian Federation, and the United States. Australian data were not available due to confidentiality reasons. OECD statistics for Cyprus were not available. Data from the Russian Federation were preliminary and considered by the OECD (2014b) to not be representative of the population. Finally, the particular characteristics of the US labour market led to a loss of $58 \%$ of observations due to employees who stated not having any contract at all. In that case, only 387 nonrandom observations would have remained in our sample, of which $31.3 \%$ presumably corresponded to temporary jobs, a percentage very different from the OECD statistic, which estimates only $4.2 \%$ temporary employment in the United States. Therefore, our main variable of interest would capture something different in the United States, not comparable to other countries. As shown by the ILO (2010) and the OECD (2006), due to very low EPL, the distinction between temporary and permanent employment is of much less significance in the United States.
} 
Table 1

Sample description.

\begin{tabular}{|c|c|c|c|c|c|c|c|c|c|}
\hline \multicolumn{2}{|c|}{ Country } & \multirow{2}{*}{$\begin{array}{l}\text { Sample obs. } \\
1269\end{array}$} & \multirow{2}{*}{$\frac{\%}{4.9}$} & \multirow{2}{*}{$\begin{array}{l}\text { Permanent } \\
1191\end{array}$} & \multirow{2}{*}{$\begin{array}{l}\% \\
93.9\end{array}$} & \multirow{2}{*}{$\begin{array}{l}\% \text { OECD stats } \\
90.7\end{array}$} & \multirow{2}{*}{$\begin{array}{l}\text { Temporary } \\
78\end{array}$} & \multirow{2}{*}{$\begin{array}{l}\% \\
6.1\end{array}$} & \multirow{2}{*}{$\frac{\% \text { OECD stats }}{9.3}$} \\
\hline 1 & Austria & & & & & & & & \\
\hline 2 & Belgium & 1216 & 4.7 & 1162 & 95.6 & 92.9 & 54 & 4.4 & 7.1 \\
\hline 3 & Canada & 1193 & 4.6 & 1073 & 89.9 & 87.0 & 120 & 10.1 & 13.0 \\
\hline 4 & Czech Republic & 1193 & 4.6 & 1029 & 86.3 & 92.6 & 164 & 13.7 & 7.4 \\
\hline 5 & Denmark & 1747 & 6.8 & 1637 & 93.7 & 92.2 & 110 & 6.3 & 7.8 \\
\hline 6 & Estonia & 1598 & 6.2 & 1453 & 90.9 & 95.3 & 145 & 9.1 & 4.7 \\
\hline 7 & Finland & 1265 & 4.9 & 1162 & 91.9 & 87.2 & 103 & 8.1 & 12.8 \\
\hline 8 & France & 1682 & 6.5 & 1536 & 91.3 & 85.6 & 146 & 8.7 & 14.4 \\
\hline 9 & Germany & 1361 & 5.3 & 1225 & 90.0 & 86.1 & 136 & 10.0 & 13.9 \\
\hline 10 & Ireland & 939 & 3.6 & 809 & 86.2 & 90.1 & 130 & 13.8 & 9.9 \\
\hline 11 & Italy & 930 & 3.6 & 839 & 90.2 & 87.1 & 91 & 9.8 & 12.9 \\
\hline 12 & Japan & 1507 & 5.8 & 1342 & 89.1 & 91.4 & 165 & 10.9 & 8.6 \\
\hline 13 & Korea & 1164 & 4.5 & 907 & 77.9 & 78.9 & 257 & 22.1 & 21.1 \\
\hline 14 & Netherlands & 1172 & 4.5 & 1035 & 88.3 & 81.4 & 137 & 11.7 & 18.6 \\
\hline 15 & Norway & 1226 & 4.7 & 1166 & 95.1 & 93.3 & 60 & 4.9 & 6.7 \\
\hline 16 & Poland & 1536 & 5.9 & 952 & 62.0 & 72.6 & 584 & 38.0 & 27.4 \\
\hline 17 & Slovak Republic & 1193 & 4.6 & 1021 & 85.6 & 93.6 & 172 & 14.4 & 6.4 \\
\hline 18 & Spain & 1096 & 4.2 & 923 & 84.2 & 78.0 & 173 & 15.8 & 22.0 \\
\hline 19 & Sweden & 1178 & 4.6 & 1101 & 93.5 & 85.7 & 77 & 6.5 & 14.3 \\
\hline \multirow[t]{2}{*}{20} & United Kingdom & 1388 & 5.4 & 1232 & 88.8 & 94.1 & 156 & 11.2 & 5.9 \\
\hline & Total & 25,853 & 100 & 22,795 & 88.2 & 87.8 & 3058 & 11.8 & 12.2 \\
\hline
\end{tabular}

positively correlated (Pearson's correlation $=0.79$ ) to that distribution in the OECD statistics published for 2012 (see Table 1). ${ }^{10}$

\subsection{Variables}

\subsubsection{Outcome variable}

On-the-job informal learning intensity is an index ${ }^{11}$ derived from the following questions; all measured on a five-point Likert scale ${ }^{12}$ :

(a) How often do you learn new work-related things from co-workers or supervisors?

(b) How often does your job involve learning-by-doing from the tasks you perform?

(c) How often does your job involve keeping up-to-date with new products or services?

This variable takes the lowest value if all three questions were answered 'never' and the highest if all were answered 'every day'. To facilitate the interpretation of results, the variable was standardised. In Table 2, which presents summary statistics, we observe that practically every person learns something on the job ( $98 \%$ informal learning incidence), with no significant difference by type of contract. Nonetheless, the mean value of informal learning intensity among temporary workers (0.07) is significantly higher than that of permanent employees $(0.01)$. In contrast, we observe that the latter participate significantly more often in formal job-related training.

\footnotetext{
10 According to OECD concepts, temporary employment includes dependent workers (i.e. wage and salary workers) whose job has a predetermined termination date or both the employer and the employee understand that the duration of the job is limited. Statistics are comparable across countries, since national definitions broadly conform to this generic definition.

11 This index was derived by the OECD using the generalised partial credit model estimated by weighted likelihood. Its validity was assessed based on crosscountry comparability, scale reliability and scale correlations (OECD, 2014b). Our findings are robust to different constructions of the index; for example, very similar results are obtained when using the standardised principal component factor of the three statements.

12 The response rate to these questions was $98 \%$, with the following answer options: (1) never, (2) less than once a month, (3) less than once a week but at least once a month, (4) at least once a week but not every day, and (5) every day.
}

\subsubsection{Explanatory variable}

The temporary contract variable is a dummy variable that takes the value one for temporary contracts and zero for permanent contracts. Temporary contracts in our sample include fixed-term positions $(90.5 \%)$ and agency work (9.5\%). ${ }^{13}$

\subsubsection{Control variables}

As suggested by the empirical human capital literature, we control for age, educational level (years of education proxied by the highest level of education obtained), educational mismatch (dummies for overeducation and undereducation),${ }^{14}$ learning attitude, ${ }^{15}$ numeracy test score as measured by the PIACC--OECD test, firm tenure, actual weekly working hours, firm size (five categories), occupation (nine ISCO one-digit categories), industry (21 ISIC one-digit categories), year of interview (dummy), and country-fixed effects.

Table 2 shows that temporary employees in our sample are generally younger and have fewer years of work experience and tenure than permanent workers. The average test scores in both numeracy and literacy are also shown to be lower among temporary workers. Moreover, among individuals in temporary positions, there is a higher share of overeducated workers and a lower proportion employed in skilled occupations, large firms, and the tertiary sector of the economy. It is worth

\footnotetext{
${ }^{13}$ The variable is derived from the survey question what kind of employment contract do you have? The answer options were (1) an indefinite contract, (2) a fixed-term contract, (3) a temporary employment agency contract, (4) an apprenticeship or other training scheme, and (5) no contract.

14 These dummies are derived from the following question: Thinking about whether this qualification is necessary for doing your job satisfactorily, which of the following statements would be truest? The answer options were (1) this level is necessary, (2) a lower level would be sufficient, and (3) a higher level would be needed.

15 This variable is a standardised index derived by the OECD (labelled learning readiness) from the following questions, all measured on a five-point Likert scale: (1) When I hear or read about new ideas, I try to relate them to real-life situations to which they might apply; (2) I like learning new things; (3) when I come across something new, I try to relate it to what I already know; (4) I like to get to the bottom of difficult things; (5) I like to figure out how different ideas fit together; and (6) if I don't understand something, I look for additional information to make it clearer. This variable was constructed by the OECD based on the work of Kirby et al. (2003). Learning attitude describes workers' interests in learning and information-processing strategies and it is considered a metacognitive ability that structures the learning process and affects learning efficiency.
} 
Table 2

Summary statistics.

\begin{tabular}{|c|c|c|c|c|c|c|c|}
\hline \multirow[t]{2}{*}{ Variable } & \multicolumn{2}{|c|}{ Permanent } & \multicolumn{2}{|c|}{ Temporary } & \multirow{2}{*}{$\begin{array}{l}\text { Diff. } \\
p \text {-value }\end{array}$} & \multicolumn{2}{|l|}{ All } \\
\hline & Mean & Std. Dev. & Mean & Std. Dev. & & Min & Max \\
\hline Informal learning incidence & 0.98 & 0.14 & 0.97 & 0.17 & 0.254 & 0 & 1 \\
\hline Informal learning intensity (original scale) & 3.40 & 1.09 & 3.51 & 1.18 & 0.001 & 1 & 5 \\
\hline Informal learning intensity (standardised index) & 0.01 & 0.95 & 0.07 & 1.06 & 0.001 & -3.28 & 2.05 \\
\hline Training (participation) $)^{\mathrm{a}}$ & 0.52 & 0.50 & 0.39 & 0.49 & 0.000 & 0 & 1 \\
\hline Missed training due to a random event ${ }^{\mathrm{a}}$ & 0.24 & 0.15 & 0.24 & 0.15 & 0.986 & 0 & 1 \\
\hline Age & 42.12 & 11.11 & 35.95 & 12.78 & 0.000 & 17 & 65 \\
\hline Years of education & 13.30 & 2.89 & 12.92 & 3.09 & 0.167 & 3 & 22 \\
\hline Work experience (years) & 21.37 & 11.68 & 14.58 & 12.54 & 0.000 & 0 & 47 \\
\hline Overeducated & 0.23 & 0.42 & 0.30 & 0.46 & 0.005 & 0 & 1 \\
\hline Undereducated & 0.07 & 0.26 & 0.06 & 0.23 & 0.111 & 0 & 1 \\
\hline Learning attitude (standardised index) & 0.00 & 0.99 & -0.02 & 1.09 & 0.221 & -6.81 & 8.81 \\
\hline Tenure (years) & 11.90 & 10.26 & 4.43 & 7.30 & 0.000 & 0 & 45 \\
\hline Weekly working hours & 42.53 & 7.29 & 42.58 & 8.36 & 0.757 & 28 & 60 \\
\hline Numeracy skills score & 285.73 & 47.99 & 270.16 & 49.29 & 0.000 & 90.41 & 414.02 \\
\hline Literacy skills score & 281.40 & 43.67 & 271.42 & 46.59 & 0.000 & 85.82 & 436.59 \\
\hline Interviewed in 2012 & 0.40 & 0.49 & 0.36 & 0.48 & 0.064 & 0 & 1 \\
\hline \multicolumn{8}{|l|}{ Occupation } \\
\hline Managers & 0.10 & 0.30 & 0.05 & 0.21 & 0.000 & 0 & 1 \\
\hline Professionals & 0.18 & 0.38 & 0.15 & 0.35 & 0.000 & 0 & 1 \\
\hline Technicians and associate professionals & 0.18 & 0.39 & 0.11 & 0.31 & 0.000 & 0 & 1 \\
\hline Clerical support workers & 0.07 & 0.25 & 0.08 & 0.27 & 0.080 & 0 & 1 \\
\hline Services and sales workers & 0.09 & 0.28 & 0.11 & 0.32 & 0.001 & 0 & 1 \\
\hline Skilled agricultural and fishery workers & 0.01 & 0.10 & 0.02 & 0.13 & 0.003 & 0 & 1 \\
\hline Craft and related trades workers & 0.18 & 0.39 & 0.22 & 0.41 & 0.000 & 0 & 1 \\
\hline Plant and machine operators & 0.13 & 0.34 & 0.17 & 0.37 & 0.000 & 0 & 1 \\
\hline Elementary occupations & 0.05 & 0.22 & 0.11 & 0.31 & 0.000 & 0 & 1 \\
\hline \multicolumn{8}{|l|}{ Industry } \\
\hline Agriculture, forestry and fishing & 0.02 & 0.13 & 0.03 & 0.16 & 0.056 & 0 & 1 \\
\hline Manufacturing & 0.30 & 0.46 & 0.30 & 0.46 & 0.358 & 0 & 1 \\
\hline Construction & 0.11 & 0.31 & 0.14 & 0.34 & 0.000 & 0 & 1 \\
\hline Sales, transport, accommodation and food services & 0.22 & 0.41 & 0.20 & 0.40 & 0.039 & 0 & 1 \\
\hline Information and communication & 0.05 & 0.21 & 0.02 & 0.16 & 0.000 & 0 & 1 \\
\hline Finance & 0.03 & 0.17 & 0.02 & 0.13 & 0.002 & 0 & 1 \\
\hline Real estate & 0.01 & 0.09 & 0.01 & 0.10 & 0.138 & 0 & 1 \\
\hline Professional, technical and administration services & 0.08 & 0.26 & 0.09 & 0.28 & 0.051 & 0 & 1 \\
\hline Public administration, education and health & 0.17 & 0.38 & 0.15 & 0.36 & 0.011 & 0 & 1 \\
\hline Other services & 0.03 & 0.17 & 0.04 & 0.20 & 0.049 & 0 & 1 \\
\hline \multicolumn{8}{|l|}{ Firm size } \\
\hline Firm size $1-10$ & 0.20 & 0.40 & 0.24 & 0.43 & 0.000 & 0 & 1 \\
\hline Firm size $11-50$ & 0.30 & 0.46 & 0.32 & 0.47 & 0.014 & 0 & 1 \\
\hline Firm size $51-250$ & 0.25 & 0.44 & 0.24 & 0.43 & 0.099 & 0 & 1 \\
\hline Firm size $251-1000$ & 0.14 & 0.35 & 0.12 & 0.33 & 0.005 & 0 & 1 \\
\hline Firm size $>1000$ & 0.10 & 0.30 & 0.07 & 0.26 & 0.000 & 0 & 1 \\
\hline Observations & 22,795 & 3058 & & 25,853 & & & \\
\hline \multicolumn{8}{|l|}{ Selection instruments } \\
\hline Unemployment rate $t-6$ (by country and age groups) & 6.39 & 4.32 & 10.66 & 7.53 & 0.000 & 0 & 0.58 \\
\hline Unemployment rate $t-6$ (standardised) & -0.08 & 0.81 & 0.70 & 1.54 & 0.000 & -1.16 & 10.17 \\
\hline EPL regular employment (index) & 2.12 & 0.56 & 2.17 & 0.54 & 0.000 & 0.92 & 3.05 \\
\hline EPL regular employment (standardised) & 0.09 & 0.99 & 0.13 & 0.98 & 0.000 & -1.89 & 1.56 \\
\hline EPL temporary employment (index) & 1.52 & 1.19 & 1.34 & 1.07 & 0.000 & 0.05 & 3.93 \\
\hline EPL temporary employment (standardised) & 0.04 & 1.00 & -0.11 & 0.98 & 0.000 & -1.19 & 2.06 \\
\hline
\end{tabular}

${ }^{a}$ Due to lower response rate, we have fewer observations for these variables $(23,232)$.

mentioning that there is no descriptive difference between permanent and temporary employees regarding years of education, undereducation, learning attitude, and working hours.

\subsubsection{Selection instrumental variables}

To exploit workers' differential exposure to potential unemployment, we use as a selection instrument in our model the annual male unemployment rate six years preceding the respondent's interview date, ${ }^{16}$

${ }^{16}$ We use unemployment data from year $t-6$ to ensure that, first, the current and past five-year age groups are equivalent but not the same cohort of individuals in which varies both between countries and within countries across fiveyear age groups. We collected these data from the OECD Statistics website.

our sample and, second, that this unemployment information is measured before the financial crisis. Therefore, unemployment rates for 2005 and 2006 were correspondingly used for individuals interviewed in 2011 and 2012. Since we exploit unemployment variation across specific labour market segments rather than changes in unemployment over time, our results are robust to the use of unemployment data before 2005. For example, similar results are obtained when using unemployment data from 2001 to 2004. 

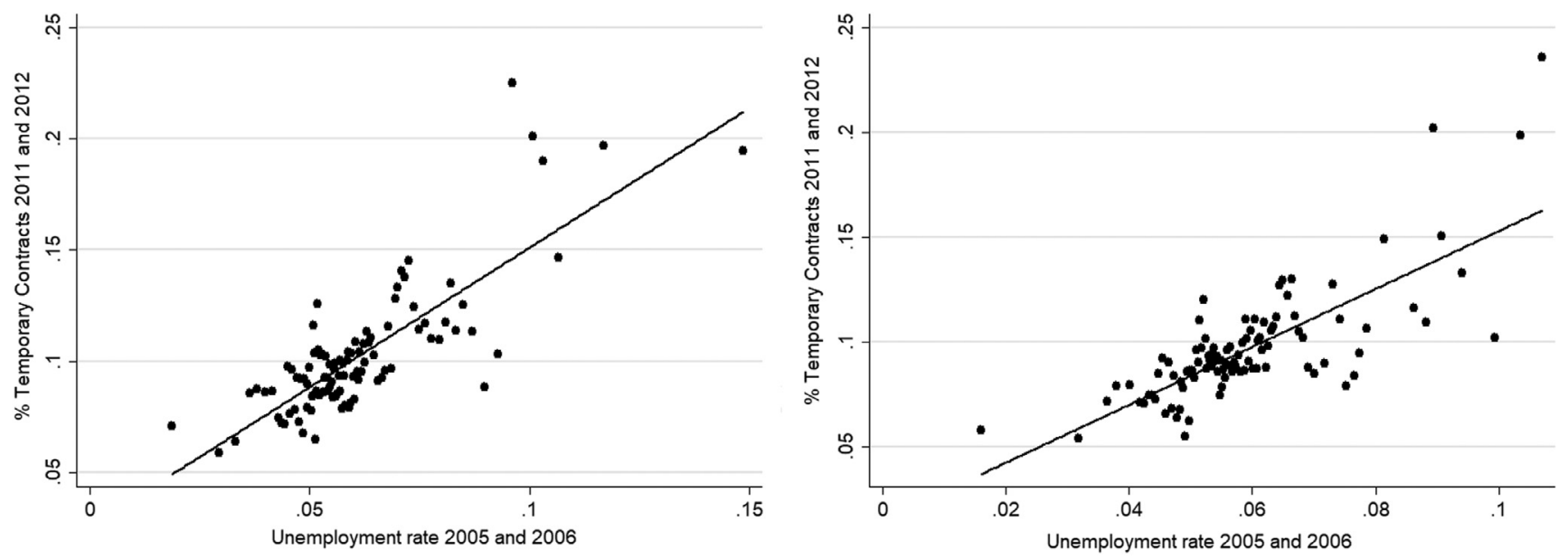

Fig. 1. Correlation graphs between unemployment rate and temporary contracts

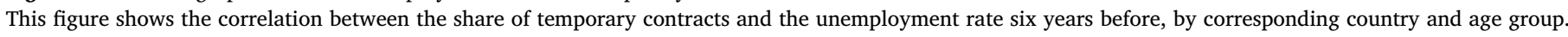
Each graph is a binned scatterplot of 100 bins. Linear estimation is shown, after controlling for age and country-fixed effects.

The unemployment rate is a relevant selection instrument for the individual probability of having a temporary contract. Unemployment measures have been shown to be correlated with the subsequent incidence of temporary employment (Wasmer, 1999; Holmlund and Storrie, 2002; Virtanen et al., 2005; Kahn, 2010). ${ }^{17}$ The average likelihood that workers will be employed in temporary jobs increases with relatively high unemployment rates. This is expected, since temporary jobs have been promoted as a mechanism to improve the labour market integration of the unemployed (Gagliarducci, 2005; Gebel, 2013) and because a higher unemployment rate often means a risk for the active working population and job seekers that reduces the chances of finding more stable employment (European Commission, 2010). If employment prospects are tight, workers anticipate scarce opportunities in the labour market; therefore, the probability of accepting temporary contracts is higher (Abraham, 1990; Holmlund and Storrie, 2002; Givord and Wilner, 2015). Moreover, if there is excess supply in the labour market, firms are more willing to make use of temporary contracts as a low-cost short-run buffer or as a probationary period (Wasmer, 1999; Gagliarducci, 2005; Givord and Wilner, 2015). ${ }^{18}$ Temporary employment then involves more employable individuals who could have had permanent contracts if the economic conditions had been better and vice versa (Wasmer, 1999; Givord and Wilner, 2015).

Table 2 shows that the average value of the unemployment rate six years prior to the respondent's interview date is three percentage points higher for the group of temporary workers than for the permanent employees in our sample. We find that the national unemployment rate by age has a significant Pearson's correlation of 0.57 with the temporary contract dummy of our sample. Fig. 1 shows this positive correlation, after controlling for age and country-fixed effects. To confirm that the positive correlation is not fully determined by the extremely high un-

\footnotetext{
17 Transitions from unemployment to temporary or permanent employment and from temporary to permanent contracts are likely to depend on the labour market's structure. If the pool of unemployed is large, transition rates from unemployment into temporary jobs are higher than the flow from unemployment to permanent jobs (Wasmer, 1999, Holmlund and Storrie, 2002). Similarly, if the unemployment rate is high, the probability that a temporary contract is converted into a permanent contract is lower (Wasmer, 1999, Givord and Wilner, 2015).

18 The greater value of hiring a worker with a temporary contract comes from the employer's right to dismiss unproductive or mismatched workers at a lower cost. In Wasmer's (1999) model, if the unemployment rate is relatively high, firms use more temporary contracts, and accordingly, the effect of a higher unemployment rate is to increase the share of temporary jobs.
}

employment rates, the left-hand graph excludes unemployment rates higher than $15 \%$, and the right-hand graph, the rates higher than $10 \%$. In Section 5, we formally confirm the existence, statistical significance and robustness of this correlation in our SRM application.

Since the exogeneity of our selection instrument cannot be tested, it could be questioned if unemployment rates at the age-group-by-country level would affect workplace informal learning at the individual level six years later - due to a link with unobserved confounding factors. The first questioning seems to be obviously related to the type of contract an employee has: If workers are aware that the past unemployment rate was relatively high for their equivalent age group, they might face tenure uncertainty that might encourage them to invest more in on-thejob learning. However, this job tenure uncertainty mainly depends on whether the job contract is permanent or temporary.

Alternatively, the exogeneity of the unemployment rate could be questioned on the basis of an indirect link with some individual or job characteristics that are omitted from Eq. (1). This should, however, not be a concern in our setting for at least two reasons. First, we are able to take account of previously neglected control variables in the temporary contracts literature, including a large set of job task-content characteristics and some further individual characteristics. Second, several studies on individuals' preferences have shown that adults' preferences at the individual level are highly stable and correlated over time and that any remaining instability is largely attributable to measurement error (De Oliveira et al., 2012; Meier and Sprenger, 2015; Chuang and Schechter, 2015; Hardardóttir, 2017). Moreover, sporadic changes in individual preferences have been shown to be related to individuals' own experiences rather than to the use of available historical data or macroeconomic developments (Bucciol and Zarri, 2015; Malmendier and Nagel, 2011, 2016). These changes have been commonly studied in relation to extreme experiences such as a natural disaster, a violent event or an economic crisis, which have been shown to be correlated to increases in risk aversion and impatience (Guisoet al., 2013; Cameron and Shah, 2015; Cohn et al., 2015; Callen et al., 2014). Individuals have also been found to be influenced more strongly by recent than distant experiences since the memory of these events vanishes over time (Malmendier and Nagel, 2011, 2016). Drastic changes in macroeconomic variables such as unemployment could then be correlated with people's subjective preferences. However, this does not hamper our empirical strategy. First, we exploit variation in unemployment across specific labour market segments rather than unemployment shocks or changes in unemployment over time. Second, the literature suggests that aggregate measures of unemployment are not expected to be correlated to individual preferences unless an individual unemployment experience occurs 
Table 3

Unemployment rate 2005/2006 and workers' personal and job-task characteristics 2011/2012.

\begin{tabular}{|c|c|c|c|c|c|c|c|c|c|c|c|c|c|c|}
\hline Unemployment rate (std.) & (1) & (2) & (3) & (4) & (6) & (7) & $(8)$ & (9) & (10) & (11) & (12) & (13) & (14) & (15) \\
\hline Job satisfaction & $\begin{array}{l}-0.002 \\
(0.003)\end{array}$ & $\begin{array}{l}0.000 \\
(0.003)\end{array}$ & & & & & & & & & & & & \\
\hline Learning motivation & $\begin{array}{l}-0.002 \\
(0.003)\end{array}$ & & $\begin{array}{l}-0.003 \\
(0.003)\end{array}$ & & & & & & & & & & & \\
\hline Social trust & $\begin{array}{l}0.003 \\
(0.003)\end{array}$ & & & $\begin{array}{l}0.003 \\
(0.003)\end{array}$ & & & & & & & & & & \\
\hline Political efficacy perception & $\begin{array}{l}0.004 \\
(0.003)\end{array}$ & & & & $\begin{array}{l}0.002 \\
(0.003)\end{array}$ & & & & & & & & & \\
\hline Health status & $\begin{array}{l}-0.005 \\
(0.005)\end{array}$ & & & & & $\begin{array}{l}-0.004 \\
(0.005)\end{array}$ & & & & & & & & \\
\hline Task flexibility & $\begin{array}{l}0.004 \\
(0.006)\end{array}$ & & & & & & $\begin{array}{l}-0.000 \\
(0.004)\end{array}$ & & & & & & & \\
\hline Task collaboration and teamwork & $\begin{array}{l}0.002 \\
(0.004)\end{array}$ & & & & & & & $\begin{array}{l}-0.000 \\
(0.003)\end{array}$ & & & & & & \\
\hline Problem-solving tasks & $\begin{array}{l}-0.001 \\
(0.004)\end{array}$ & & & & & & & & $\begin{array}{l}-0.004 \\
(0.003)\end{array}$ & & & & & \\
\hline Planning tasks & $\begin{array}{l}-0.001 \\
(0.002)\end{array}$ & & & & & & & & & $\begin{array}{l}-0.001 \\
(0.002)\end{array}$ & & & & \\
\hline Physical tasks & $\begin{array}{l}0.004 \\
(0.003)\end{array}$ & & & & & & & & & & $\begin{array}{l}0.002 \\
(0.003)\end{array}$ & & & \\
\hline Numeracy-related tasks & $\begin{array}{l}0.002 \\
(0.004)\end{array}$ & & & & & & & & & & & $\begin{array}{l}-0.002 \\
(0.003)\end{array}$ & & \\
\hline Literacy-related tasks & $\begin{array}{l}-0.004 \\
(0.004)\end{array}$ & & & & & & & & & & & & $\begin{array}{l}-0.005 \\
(0.006)\end{array}$ & \\
\hline ICT-related tasks & $\begin{array}{l}-0.002 \\
(0.005)\end{array}$ & & & & & & & & & & & & & $\begin{array}{l}-0.003 \\
(0.003)\end{array}$ \\
\hline Other controls & yes & yes & yes & yes & yes & yes & yes & yes & yes & yes & yes & yes & yes & yes \\
\hline$N$ & 23,020 & 25,846 & 25,850 & 25,795 & 25,748 & 25,845 & 25,413 & 25,817 & 25,804 & 23,448 & 25,840 & 25,853 & 25,852 & 25,853 \\
\hline$R^{2}$ & 0.835 & 0.835 & 0.835 & 0.835 & 0.835 & 0.835 & 0.835 & 0.836 & 0.836 & 0.834 & 0.835 & 0.835 & 0.835 & 0.835 \\
\hline
\end{tabular}

Notes. ${ }^{*} p<0.10,{ }^{* *} p<0.05,{ }^{* * *} p<0.01$. Robust standard errors in parentheses, clustered at the age-group-by-country level. The standardised unemployment rate (at the age-group-by-country level, six years prior to the interview) is the dependent variable. Other controls include age and country-fixed effects.

(Bucciol and Zarri, 2015; Malmendier and Nagel, 2011, 2016; Hardardóttir, 2017). Third, it is important to note that the exogeneity of our instrument is further reinforced by using its lagged nature, that is, aggregate unemployment rates being measured six years preceding the survey generating our main data - which means that the current and past five-year age groups are equivalent but not the same cohort of individuals ${ }^{19}$ - and prior to the occurrence of the global financial crisis.

Although we cannot formally test for the exogeneity of the unemployment rate at the age-group-by-country level, we can provide some evidence that this instrument is orthogonal to some obvious aspects such as skill levels, job satisfaction, learning motivation, or the job's tasks six years later. Table 3 reports the results of a battery of OLS regressions with our instrument as the dependent variable and some individual and task characteristics that could influence the opportunities and motivation for informal learning as explanatory variables. These results confirm the intuition that the unemployment rate at time $t-6$ does not correlate significantly with any of these observable individual characteristics, whether the explanatory variables are included all together or one by one. This suggests that our selection instrument is likely to be orthogonal to other unobservable characteristics of similar nature. In principal, we could consider including the variables in Table 3 as control variables in our main model, but we prefer to exclude them since some of them could induce further endogeneity, whereas others could capture the impact of more relevant general variables, such as the employee's occupation or learning attitude. ${ }^{20}$

An additional argument that could question the validity of our exclusion restriction relates to the technology of skill development over the life cycle (Cunha and Heckman, 2007). If acquired skills raise both

\footnotetext{
19 e.g. for employees in the age 35-39 interviewed in 2011 in our sample, we assign as instrument the country unemployment rate of those in the age 35-39 in 2005, when the employees referred were 29-33 years old.

${ }^{20}$ Including these variables, however, does not substantially change our main results. See Section 5.4.2.
}

the level and productivity of subsequent learning investments in life, individuals exposed to a high level of unemployment for their age group may feel pushed to invest more in schooling, thus boosting their accumulation of human capital process over their life span. This however does not invalidate our exclusion restriction since not only individuals' years of education but also their skill levels are properly accounted for in our specification. A high level of unemployment could also lead to agetargeted training policies for the unemployed. This might again lead to sub-groups of the population with a boosted accumulation of human capital. If this would not be correctly captured by the observable characteristics included in $X$ (e.g. skill level, occupation, industry), potential differences in human capital accumulation within age groups could pose a threat to the validity of our instrument. Table 3 partly shows that this is not likely to be the case because, as we have explained, this argument is related to individuals' own experience of unemployment and the current and past five-year age groups do not refer to the same cohort of individuals in our setting. Nonetheless, to provide more insight into this discussion, we perform some analyses using information on training participation among the unemployed individuals in our dataset. As shown in Table A1, there does not seem to be a significant association between the contemporary (2011-2012) unemployment rates at the age-groupby-country level and the participation in (job-related) training among the unemployed individuals.

Moreover, as suggested in the literature, training programs for the unemployed in OECD countries are typically targeted on unemployment benefit recipients. Age does not usually define the main target groups and when it does, it refers to the more generic categorisation (e.g. youth, younger adults and older adults). These training programmes more often aim at a rapid reintegration to the labour market (job-search training and tackling skill deficits) instead of human capital accumulation. Studies that evaluate the effectiveness of these programs find that variation in participation is largely explained by the different institutional environments and individual characteristics and preferences, including individual unemployment duration history, educational level, fam- 
ily income, among others (Heckman and Smith, 2004; OECD, 2013b; Caliendo and Schmidl, 2016). Based on this discussion, we consider our selection instrument to be credibly valid.

Finally, we estimate an alternative specification in which we use the unemployment rate interacted with the OECD EPL indexes for permanent and temporary employment as selection instrument. ${ }^{21}$ With this instrument we build on the expectation that the relation between unemployment and the probability of having a temporary contract may differ by country because of the strictness of EPL. Stricter rules applicable to permanent (temporary) employment may tend to increase (decrease) the incidence of temporary work and affect the extent to which temporary contracts are converted into permanent ones (Booth et al., 2002; Holmlund and Storrie, 2002; OECD, 2004; Gagliarducci, 2005; Kahn, 2010; Sala et al., 2012). In Table 2 we observe that, indeed, the average value of EPL applicable to permanent (temporary) employment is slightly higher (lower) for the group of temporary workers in our sample.

\section{Empirical results}

\subsection{On-the-job informal learning intensity}

Our main results are reported in Table 4. The first specification gives the estimates of an ordinary OLS regression. Specifications (2) and (3) show the coefficients from standard 2SLS estimations. Specifications (4) and (5) provide the FIML results obtained from our identification strategy, that is, the endogenous SRM described in Section 3. Panel A of Table 4 shows the linear estimates of the informal learning equation and Panel B the corresponding linear/probit estimates of the temporary contract equation. In all the regressions, standard errors are clustered at the age-group-by-country level which is the exact level of variation of the selection instrument.

The results in Table 4 provide clear evidence of a significant difference in on-the-job informal learning between temporary and permanent employees, in favour of those who have a temporary contract. Compared with the OLS estimates, the coefficients from the estimations that account for the endogeneity of temporary contracts are adjusted upwards, in line with the negative bias we expected.

As discussed in Section 3, we consider the FIML estimates presented in columns (4) and (5) the preferred regressions. The main result of our study is the positive and significant difference in the intensity of on-thejob informal learning between workers with temporary and permanent contracts. Specifications (4) and (5) show that, once selection into the contract type is controlled for, the estimated ATE of interest increases from 0.09 to 0.22 . This result implies that workers in temporary jobs invest, on average, 0.22 of a standard deviation more in on-the-job informal learning than their counterparts in permanent employment. ${ }^{22}$ The size of this coefficient seems to be substantial if we consider that it is similar to the impact of approximately 10 years of schooling.

We consider the FIML estimates more appropriate for various reasons. First, the nonlinear prediction of selection into temporary contracts is more accurate. Whereas the linear predictions from the 2SLS first stage range from -1.68 to 0.71 (with a mean standard error of 0.09), leaving $26 \%$ of the sample below zero, the probit probabilities from the FIML estimations range from 0.01 to 0.84 (with a mean standard error of 0.02), which provides better common support. Second, the

\footnotetext{
21 EPL for permanent employment is a weighted indicator concerning the regulations for individual and collective dismissals. EPL for temporary employment is a weighted indicator concerning regulation on the use of fixed-term and temporary agency contracts.

${ }^{22}$ The coefficients for temporary contracts in specifications (4) and (5) are not significantly different from each other. Including the EPL measures as selection instruments has very little effect, which suggests that the country fixed effects absorb most of the explanatory power of the national differences in employment regulations.
}

sizes of the instrument coefficients differ significantly between the 2SLS and FIML specifications. In column (4), for instance, an increase of one standard deviation in the unemployment rate, on average, increases the probability of being in a temporary contract by 1.5 percentage points. In column (2), the same effect predicted by the 2SLS is 4.8 percentage points, three times bigger. The size of the probit marginal effect is closer to that in related research, for example, Kahn's (2010). Third, as we observe, the 2SLS approach inflates the estimate for temporary contracts, which might be due to the less precise prediction provided in the selection equation and because the use of a continuous instrument for the temporary contract variable makes the local ATE estimation less straightforward. ${ }^{23}$ Moreover, as we show in Section 5.4, there is some important heterogeneity in our application, which significantly reduces the efficiency of the standard IV estimation. Fourth, we observe some implausible estimates in the 2SLS outcome equations, such as positive nonsignificant coefficients for age and tenure. Fifth, the Wald tests for specifications (4) and (5) indicate with 95\% confidence that we can reject the null hypothesis of no correlation between the errors of the temporary contract and informal learning equations, so that our instrumented endogenous SRM fits well overall. The estimated correlation between the temporary contract equation errors and the outcome errors $\rho$ is negative $(-0.09)$, indicating that unobservables that raise informal learning tend to occur with unobservables that lower temporary contract selection. This finding is coherent with our hypothesis on the unobservables mentioned in Section 3; for instance, people with greater ability or lower time discount rate are less likely to be selected into temporary jobs and are at the same time more likely to invest in human capital on the job (Mincer 1997). Last but not least, in contrast to the FIML approach 2SLS does not provide ATEs but, instead, local ATEs, the former being more policy relevant in the context of our research question.

Concerning the admissibility of our instrument, the Wald and F-tests after nonlinear and linear first-stage estimations, respectively show that the unemployment rate, in addition to the other covariates, makes a significant contribution to the temporary contract prediction. Furthermore, the LR-tests in the models (4) and (5) confirm that the instrumented models fit the data significantly better than the constrained model that does not include any instrument.

Most of our control variables affect the dependent variable according to the expectations from human capital theory (e.g. Ben-Porath, 1967; Heckman, 1976; Killingsworth, 1982). We find a quadratic relation between on-the-job informal learning and age, suggesting a minimum turning point of investments at the end of employees' working life. ${ }^{24}$ Years of education are positively correlated with learning in the workplace, although overeducated employees tend to invest less in informal learning than workers in a well-matched job, while undereducated employees invest more. ${ }^{25}$ There is also a positive relation between informal learning intensity and learning attitude and working hours and a negative relation with tenure and the numeracy skills score. We also find that informal learning tends to be significantly higher for individuals employed in high-skilled occupations and larger firms.

As discussed in the introduction, our main finding could be rationalised by several mechanisms. Even though we cannot test all of them with our data, in Sections 5.3 and 5.4, we present additional results that provide further insights into these possible mechanisms.

\footnotetext{
${ }^{23}$ Because of the continuous measures of unemployment and EPL, the local ATE is not very informative since it refers to an unidentifiable segment of the population.

${ }^{24}$ The estimated average minimum (68 years) at which informal learning starts increasing with age is not very meaningful. However, as shown in Section 5.4.1, this is because investments in informal learning differ by age between permanent and temporary employees.

25 Our estimations control for the fact that workers have a job at the appropriate educational level. Nonetheless, estimations that do not control for educational mismatches yield to very similar results (see Table A2).
} 
Table 4

Estimations of on-the-job informal learning.

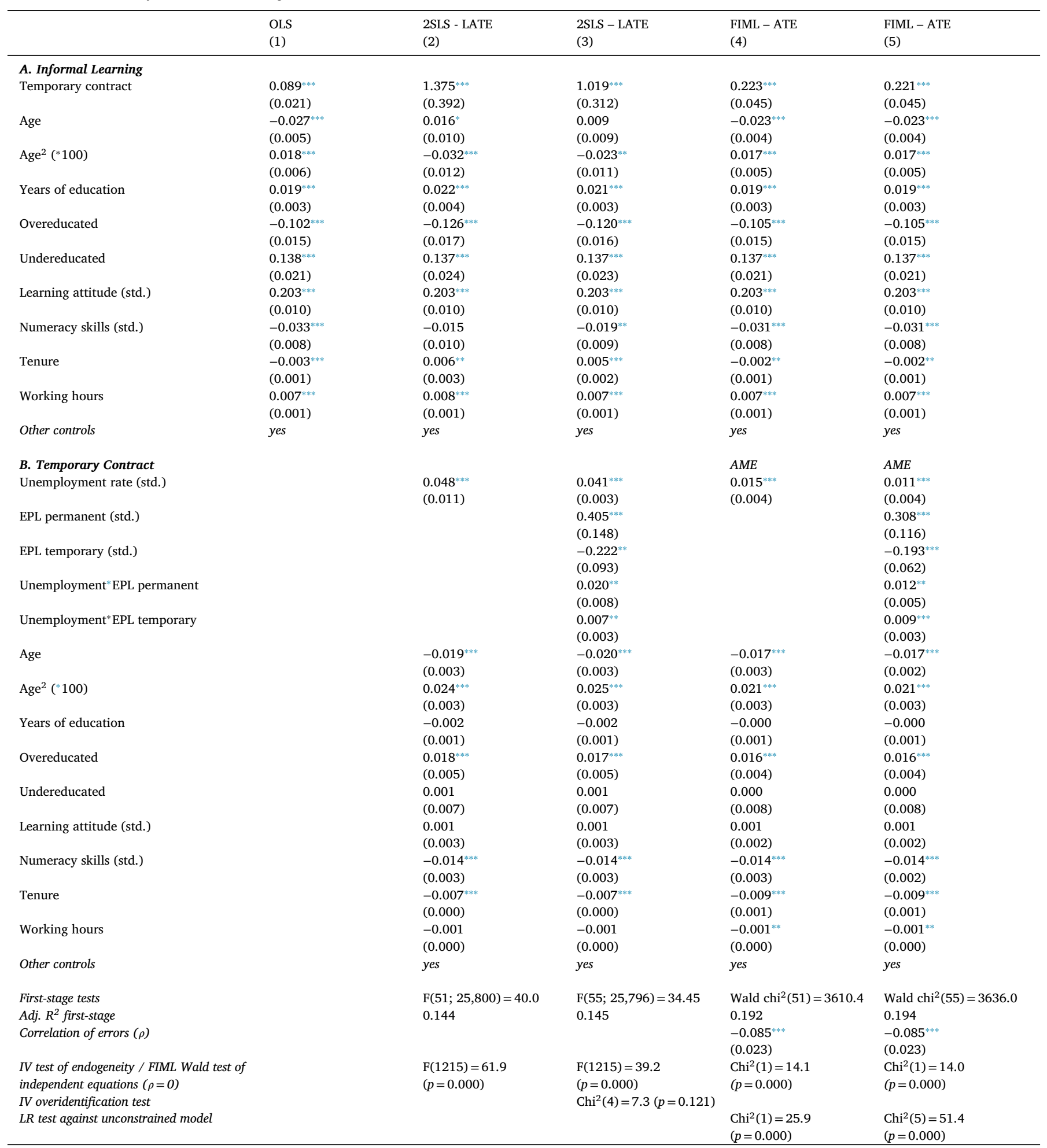

Notes. ${ }^{*} p<0.10,{ }^{* *} p<0.05,{ }^{* * *} p<0.01$. Robust standard errors in parentheses, clustered at the age-group-by-country level. The informal learning dependent variable is standardised. The standardised unemployment rate (at the age-group-by-country level, six years prior to the interview) is used as a selection instrument in columns (2) and (4) and columns (3) and (5) add the interaction of the latter with the corresponding standardised EPL indexes for permanent and temporary employment. All the estimations include a constant term. Other controls include dummies for occupation, industry, firm size, year of interview and country-fixed effects. The term AME denotes average marginal effects. $\mathrm{N}=25,853$. 


\subsection{Robustness of main results}

In assessing the robustness of our main findings, the most important concern is the possible misspecification error of the contract selection Eq. (2). The first issue we address is the sensitivity of our main estimations to different specifications of the probit model. We tested a range of models in contrast to our FIML estimates in Table 4 and present the results in the Appendix A, Table A2.

Specifications in Panel A of Table A2 exclude the variables we included as determinants of temporary contract selection in our main estimations in Table 4. The table shows that excluding these regressors only from the selection Eq. (2) slightly lowers the estimated ATE. However, the resulting coefficients are not significantly different from our main estimate, which suggests that our model is robust. Only when country dummies are excluded from the probit model, we observe an increase in the estimated ATE from 0.22 to 0.28 . This suggests that country-fixed effects are important controls for the type of contract selection. The increase in the ATE is, however, not excessive, since the unemployment rate seems to capture these country differences in the absence of the country-fixed effects in the probit equation (the average marginal effect of the unemployment rate increases from 0.015 to 0.027 ).

Specifications in Panel B of Table A2 show how the main estimated coefficient of temporary contracts changes with the gradual introduction of control variables. Panel $\mathrm{C}$ shows the results of various alternative specifications. First, we estimate our main model including age as a categorical variable (11 dummies of five-year age groups) instead of the continuous variable. The resulting coefficient is 0.208 , with a standard error of 0.046; statistically the same size and significance of our main estimates in Table 4. Second, we include a polynomial of the second order for tenure in an alternative specification. Again, the resulting coefficients are very similar to our main results in Table 4.

Last, we run several other sensitivity analyses of our main specification, using various restricted samples. The results are shown in Panel D of Table A2. First, we exclude the individuals with a corresponding unemployment rate higher than $20 \%$ and $10 \%$, as previously described in Fig. 1. The resulting estimates are slightly lower but still the estimated ATE of interest remains significant and of similar magnitude as that of Table 4. We also estimate our main model excluding non-European countries (i.e. Canada, Japan, and Korea). In this case, the estimate of temporary contracts rises from 0.22 to 0.28 of a standard deviation. This indicates, as expected, some heterogeneity of the effect between countries, and shows the robustness of our main result. To test for the possibility that our results are driven by a few countries, we continue with other specifications that exclude the countries with the largest shares of temporary employees, that is, Poland, Korea, Spain and Slovak Republic. Similarly, in the next robustness test, we also exclude from our sample those countries with the highest unemployment rates: Poland, Germany and Slovak Republic. Finally, we test our main model restricting the sample to prime age workers, i.e., employees in the age ranges 20-64, 25-64, and 25-54. In all cases, the estimated ATE of interest remains significant and of similar magnitude as that of Table 4. Only the estimate from the sample of workers in ages 25-64 slightly declines from 0.22 to 0.18 of a standard deviation, which is explained later in Section 5.4 .1 by the decreasing effect of temporary contracts on informal learning with age. This can be verified here by observing the results of the prime age workers (25-54) sample, which gives a significant coefficient of 0.21 of a standard deviation. It is important to note that the predicted values of $\rho$ remain negative in all these robustness specifications presented in Table A2, indicating that our main results hold. The Wald tests are all significant with $95 \%$ confidence.

\subsection{Informal learning and training: substitution or complementarity?}

A plausible explanation for temporary workers' higher intensity of informal learning could be that, for workers with temporary contracts, on-the-job informal learning substitutes for the lack of formal training. We test for this possibility in this section.

\subsubsection{Training incidence}

In this subsection, we perform estimations to first validate in our sample the negative association of temporary contracts with training participation ${ }^{26}$ found in various previous studies.

The results in Table 5 confirm that the temporary contract indicator in our sample yields the expected negative coefficient. The FIML results in columns (2) and (3) indicate that the probit estimation (1) is biased downwards to some extent. Once the selection into the contract types is controlled for, we find that workers in temporary jobs are, on average, 2.5 percentage points less likely to participate in training activities than those in permanent employment are. The coefficients of the covariates included in these estimations are consistent with human capital theory and findings in previous empirical literature (e.g. Booth, 1991; Green, 1993).

The negative value of $\rho$ suggests that unobservables that decrease temporary contract selection probably occur with unobservables that increase training participation, as suggested in Section 3. For the FIML ${ }^{27}$ specifications (3) and (4), the Wald tests indicate that we can reject the null hypothesis of $\rho=0$ with $95 \%$ confidence.

\subsubsection{Complementarity}

The finding that workers with temporary contracts are less likely to participate in training but engage more intensively in informal learning raises the question of whether informal learning is a training substitute for temporary workers.

To answer this question, we first observe whether there is a difference in the informal learning intensity of employees who undertook training and those who did not. Fig. 2 illustrates this difference among temporary and permanent workers separately. This figure suggests complementarity between training and informal learning, regardless of the type of contract, since the intensity of investments in the latter is shown to be consistently larger when following training. This result holds for both temporary and permanent employees.

To test whether there is, indeed, complementarity between training and informal learning, we include training participation and its interaction with temporary contracts in our main equation for informal learning. To provide reliable results, we use an additional selection instrument to correct for the potential endogeneity of formal training in the informal learning equation. To this end, we apply the identification approach of Leuven and Oosterbeek (2008), which suggests that having missed out on formal training opportunities for unexpected reasons is a valid approximation to a random assignment to training. This is achieved by using the information obtained through two designed survey questions. The first is whether there was any training related to work that the respondent wanted to attend but did not do so. The second asks whether this non-participation was due to some random event such as family circumstances, transient illness, or any other unexpected personal or job-related incident. As shown in Panel C of Table 6, having

\footnotetext{
${ }^{26}$ Our training variable is a dummy of participation in job-related training during the previous 12 months. It is based on the following questions: During the last 12 months, have you (1) participated in courses conducted through open or distance education, (2) attended any organised sessions for on-the-job training, (3) participated in seminars or workshops, or (4) participated in courses or private lessons not already reported? This variable takes the value one if the individual participated in any of these job-related activities and zero otherwise. The response rate to these questions was $90 \%$, which reduced the sample size for this analysis to 23,232 observations.

27 Since the endogenous SRM for a binary outcome follow a different structure, the Stata command etregress is inappropriate. We therefore used the gllamm program to fit the correspondent models (3) and (4). For a detailed description of this command, see Rabe-Hesketh et al. (2005) and Miranda and RabeHesketh (2006).
} 
Table 5

Estimations of job-related training participation.

\begin{tabular}{|c|c|c|c|}
\hline & Probit (1) & FIML (2) & FIML (3) \\
\hline A. Training & AME & AME & AME \\
\hline Temporary contract & $\begin{array}{l}-0.054^{* * *} \\
(0.010)\end{array}$ & $\begin{array}{l}-0.026^{* * *} \\
(0.010)\end{array}$ & $\begin{array}{l}-0.025^{* * *} \\
(0.010)\end{array}$ \\
\hline Age & $\begin{array}{l}0.010^{* * * *} \\
(0.002)\end{array}$ & $\begin{array}{l}0.009^{* * * *} \\
(0.002)\end{array}$ & $\begin{array}{l}0.009^{* * * *} \\
(0.002)\end{array}$ \\
\hline $\operatorname{Age}^{2}(* 100)$ & $\begin{array}{l}-0.015^{* * * *} \\
(0.002)\end{array}$ & $\begin{array}{l}-0.013^{* * * *} \\
(0.002)\end{array}$ & $\begin{array}{l}-0.013^{* * * *} \\
(0.002)\end{array}$ \\
\hline Years of education & $\begin{array}{l}0.012^{* * *} \\
(0.001)\end{array}$ & $\begin{array}{l}0.014^{* * * *} \\
(0.001)\end{array}$ & $\begin{array}{l}0.014^{* * * *} \\
(0.001)\end{array}$ \\
\hline Overeducated & $\begin{array}{l}-0.017^{* *} \\
(0.007)\end{array}$ & $\begin{array}{l}-0.016 \text { *** } \\
(0.005)\end{array}$ & $\begin{array}{l}-0.016^{* * * *} \\
(0.005)\end{array}$ \\
\hline Undereducated & $\begin{array}{l}0.028^{* * *} \\
(0.011)\end{array}$ & $\begin{array}{l}0.025^{\text {**** }} \\
(0.008)\end{array}$ & $\begin{array}{l}0.025 * * * \\
(0.008)\end{array}$ \\
\hline Learning attitude (std.) & $\begin{array}{l}0.035^{* * *} \\
(0.004)\end{array}$ & $\begin{array}{l}0.034^{* * * *} \\
(0.003)\end{array}$ & $\begin{array}{l}0.034^{* * * *} \\
(0.003)\end{array}$ \\
\hline Numeracy skills (std.) & $\begin{array}{l}0.033^{* * * *} \\
(0.004)\end{array}$ & $\begin{array}{l}0.029^{* * * *} \\
(0.000)\end{array}$ & $\begin{array}{l}0.029^{* * * *} \\
(0.000)\end{array}$ \\
\hline Tenure & $\begin{array}{l}0.002^{* * * *} \\
(0.000)\end{array}$ & $\begin{array}{l}0.002^{* * *} \\
(0.000)\end{array}$ & $\begin{array}{l}0.002^{* * * *} \\
(0.000)\end{array}$ \\
\hline Working hours & $\begin{array}{l}0.003^{* * * *} \\
(0.000)\end{array}$ & $\begin{array}{l}0.003^{* * * *} \\
(0.000)\end{array}$ & $\begin{array}{l}0.003^{* * * *} \\
(0.000)\end{array}$ \\
\hline Other controls & yes & yes & yes \\
\hline B. Temporary Contract & & AME & AME \\
\hline Unemployment rate (std.) & & $\begin{array}{l}0.014^{* * * *} \\
(0.003)\end{array}$ & $\begin{array}{l}0.011^{* * * *} \\
(0.003)\end{array}$ \\
\hline EPL permanent (std.) & & & $\begin{array}{l}0.382^{* * *} \\
(0.130)\end{array}$ \\
\hline EPL temporary (std.) & & & $\begin{array}{l}-0.230^{* * *} \\
(0.079)\end{array}$ \\
\hline Unemployment" & & & $0.011^{* *}$ \\
\hline EPL temporary & & & $(0.005)$ \\
\hline Unemployment" & & & $0.012^{* * *}$ \\
\hline EPL temporary & & & $(0.003)$ \\
\hline Other controls & & yes & yes \\
\hline First-stage tests & & Wald $\operatorname{chi}^{2}(51)=3221.3$ & Wald $\operatorname{chi}^{2}(55)=3248.3$ \\
\hline Adj. R2 first-stage & & 0.192 & 0.193 \\
\hline Correlation of errors $(\rho)$ & & $\begin{array}{l}-0.078^{* *} \\
(0.035)\end{array}$ & $\begin{array}{l}-0.082^{* *} \\
(0.037)\end{array}$ \\
\hline Wald test of independent equations $(\rho=0)$ & & $\mathrm{Chi}^{2}(1)=4.12(\mathrm{p}=0.042)$ & $\mathrm{Chi}^{2}(1)=4.05(\mathrm{p}=0.044)$ \\
\hline LR test against unconstrained model & & $\operatorname{LR~} \operatorname{chi}^{2}(1)=10.2(p=0.001)$ & $\operatorname{LR~} \operatorname{chi}^{2}(5)=18.8(p=0.002)$ \\
\hline
\end{tabular}

Notes. ${ }^{*} p<0.10,{ }^{* *} p<0.05,{ }^{* * *} p<0.01$. Robust standard errors in parentheses, clustered at the age-group-bycountry level. The training participation dependent variable is binary. The standardised unemployment rate (at the age-group-by-country level, six years prior to the interview) is used as a selection instrument in column (3) and column (4) adds the interaction of the latter with the corresponding standardised EPL indexes for permanent and temporary employment. All the estimations include a constant term and the same control variables as reported in Table 4. The term AME denotes average marginal effects. $\mathrm{N}=23,232$.
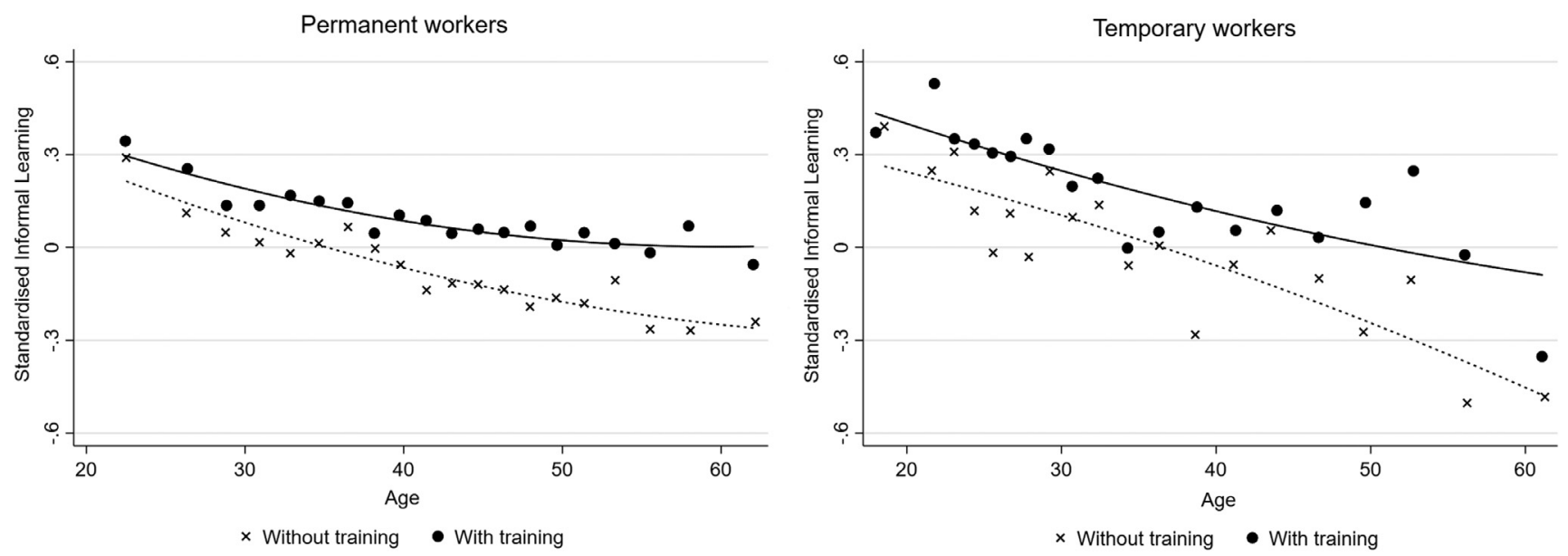

Fig. 2. Complementarity between training and informal learning by type of contract. 
Table 6

Estimations of complementarity between training and informal learning.

\begin{tabular}{|c|c|c|c|c|}
\hline & FIML (1) & FIML (2) & FIML (3) & FIML (4) \\
\hline \multicolumn{5}{|l|}{ A. Informal Learning } \\
\hline \multirow[t]{2}{*}{ Temporary contract } & $0.224^{* * * *}$ & $0.221^{* * *}$ & $0.220^{* * *}$ & $0.217^{* * * *}$ \\
\hline & $(0.051)$ & $(0.050)$ & $(0.045)$ & $(0.044)$ \\
\hline \multirow[t]{2}{*}{ Training } & $0.190^{* * * *}$ & $0.190^{* * * * *}$ & $0.074^{* * * *}$ & $0.074^{* * * *}$ \\
\hline & $(0.014)$ & $(0.014)$ & $(0.015)$ & $(0.015)$ \\
\hline \multirow[t]{2}{*}{ Training*Temporary contract } & 0.001 & 0.001 & -0.009 & -0.009 \\
\hline & $(0.039)$ & $(0.039)$ & $(0.042)$ & $(0.042)$ \\
\hline Other controls & yes & yes & yes & yes \\
\hline B. Temporary Contract & $A M E$ & $A M E$ & $A M E$ & $A M E$ \\
\hline \multirow[t]{2}{*}{ Unemployment rate (std.) } & $0.014^{* * * *}$ & $0.011^{\text {**** }}$ & $0.014^{* * * *}$ & $0.010^{* * * *}$ \\
\hline & $(0.003)$ & $(0.003)$ & $(0.003)$ & $(0.003)$ \\
\hline \multirow[t]{2}{*}{ EPL permanent (std.) } & & $0.372^{* * * *}$ & & $0.361^{* * * *}$ \\
\hline & & $(0.129)$ & & $(0.131)$ \\
\hline \multirow[t]{2}{*}{ EPL temporary (std.) } & & $-0.232^{* * * *}$ & & $-0.221^{* * * *}$ \\
\hline & & $(0.074)$ & & $(0.076)$ \\
\hline \multirow[t]{2}{*}{ Unemployment"EPL permanent } & & $0.011^{* *}$ & & $0.011^{* *}$ \\
\hline & & $(0.005)$ & & $(0.005)$ \\
\hline \multirow[t]{2}{*}{ Unemployment* EPL temporary } & & $0.011^{* * * *}$ & & $0.011^{* * * * *}$ \\
\hline & & $(0.003)$ & & $(0.003)$ \\
\hline Other controls & yes & yes & yes & yes \\
\hline C. Training & & & $A M E$ & $A M E$ \\
\hline \multirow[t]{2}{*}{ Training missed (random event) } & & & $0.064^{* * * *}$ & $0.064^{* * *}$ \\
\hline & & & $(0.023)$ & $(0.023)$ \\
\hline Other controls & yes & yes & yes & yes \\
\hline \multirow[t]{2}{*}{ Correlation of errors $(\rho)$} & $-0.082^{* * *}$ & $-0.079^{* * * *}$ & $-0.082^{* * * *}$ & $-0.081^{* * *}$ \\
\hline & $(0.022)$ & $(0.022)$ & $(0.022)$ & $(0.022)$ \\
\hline Wald test of independent equations $(\rho=0)$ & $\mathrm{Chi}^{2}(1)=13.9(p=0.000)$ & $\mathrm{Chi}^{2}(1)=13.6(p=0.000)$ & $\mathrm{Chi}^{2}(1)=13.4(p=0.000)$ & $\mathrm{Chi}^{2}(1)=13.2(p=0.000)$ \\
\hline
\end{tabular}

Notes. ${ }^{*} p<0.10,{ }^{* *} p<0.05,{ }^{* * *} p<0.01$. Robust standard errors in parentheses, clustered at the age-group-by-country level. The training participation dependent variable is binary. The standardised unemployment rate (at the age-group-by-country level, six years prior to the interview) is used as a selection instrument in columns (1) and (3), and columns (2) and (4) add the interaction of the latter with the corresponding standardised EPL indexes for permanent and temporary employment. The training missed independent variable is binary. All the estimations include a constant term and the same control variables as reported in Table 4. The term AME denotes average marginal effects. $\mathrm{N}=23,232$.

missed a training activity due to a random or unexpected event indeed increases the probability of training participation by approximately 6 percentage points.

Panel A of Table 6 shows that the positive relation between informal learning and job-related training holds after controlling for various individual and employer characteristics. Specifications (3) and (4) that account for the endogeneity of both temporary contracts and training participation show that, on average, participation in training activities increases informal learning by 0.74 of a standard deviation. The magnitude of this complementarity does not differ by type of contract, since the interaction term is close to zero and statistically insignificant. This finding shows that both the direction and size of the complementarity between informal learning and job-related training are equal for temporary and permanent employees, which suggests that the higher informal learning investment of temporary workers does not seem to substitute for their lack of formal training. Moreover, this result indicates that temporary workers engage more intensively in informal learning, even after controlling for training participation.

\subsection{Heterogeneous effects in informal learning}

To provide further insights into the possible mechanisms that could explain our main result, we analyse two types of heterogeneity: first, the heterogeneous learning investments of temporary and permanent workers that could result from observed individual and job-content characteristics, which allows us to distinguish between ATE and ATT; and, second, heterogeneous effects that could result from unobserved personal characteristics, which enable us to estimate MTEs.

\subsubsection{Heterogeneous workers}

Although temporary workers are, on average, more intensively engaged in informal learning, this could differ among workers with dif- ferent characteristics. Temporary employees could, for instance, have different expectations for their career prospects. If that is the case, we might expect younger workers and those with shorter tenure to have stronger incentives to engage in informal learning when they are employed in a temporary job, since this might help them to acquire a permanent contract.

To investigate this heterogeneity, we estimate some endogenous SRM of informal learning that allow covariates to vary by contract type, as explained in Section 3. The significant interaction results are shown in Table 7, which indicate that when allowing for heterogeneous responses to temporary contracts, our main conclusion holds. Both the ATE and ATT remain significant and positive, the latter being of similar size to our estimation in Table 4. These heterogeneous models of informal learning show that the coefficients of age, tenure, and working hours ${ }^{28}$ differ by type of contract, while years of education, educational mismatches, learning attitude and numeracy skills do not. These results confirm our expectations that the rates at which informal learning decreases with age $\mathrm{e}^{29}$ and tenure are significantly greater for those with a temporary contract. This finding suggests that our main result is particularly driven by temporary employees who are younger and have lower tenure. More precisely, being a year older and having one additional year of tenure decreases informal learning by 0.026 and 0.008 of a standard deviation, respectively, in the case of temporary workers, whereas,

\footnotetext{
${ }^{28}$ Informal learning increases with working hours only in the case of permanent workers. The number of working hours does not seem to affect the informal learning intensity of temporary employees.

29 Table 7 also shows that the coefficient of age squared is not significantly different from zero for temporary employees, suggesting that the minimum turning point of learning investments at the end of employees' working lives holds only for workers with a permanent contract.
} 
Table 7

Estimations of on-the-job informal learning with heterogeneous employees.

\begin{tabular}{|c|c|c|}
\hline & FIML (1) & FIML (2) \\
\hline \multicolumn{3}{|l|}{ A. Informal Learning } \\
\hline \multirow[t]{2}{*}{ ATE } & $0.179^{* * * *}$ & $0.179^{* * * *}$ \\
\hline & $(0.047)$ & $(0.047)$ \\
\hline ATT & $\begin{array}{l}\mathbf{0 . 2 0 6} 6^{\text {**** }} \\
(0.046)\end{array}$ & $\begin{array}{l}\mathbf{0 . 2 0 6 * * *} \\
(0.046)\end{array}$ \\
\hline \multirow[t]{2}{*}{ Age } & $-0.022^{* * * *}$ & $-0.022^{* * * *}$ \\
\hline & $(0.004)$ & $(0.004)$ \\
\hline Age $^{*}$ TC & $\begin{array}{l}-0.004^{* *} \\
(0.002)\end{array}$ & $-0.004^{* *}$ \\
\hline $\operatorname{Age}^{2}(* 100)$ & $0.018^{* * * * *}$ & $0.018^{* * * *}$ \\
\hline $\operatorname{Age}^{2}(* 100) * \mathrm{TC}$ & $\begin{array}{l}(0.005) \\
-0.018^{* * * * *} \\
(0.006)\end{array}$ & $\begin{array}{l}(0.005) \\
-0.018^{* * * *} \\
(0.006)\end{array}$ \\
\hline Tenure & $\begin{array}{l}-0.002^{* * * *} \\
(0.001)\end{array}$ & $\begin{array}{l}-0.002^{\text {k*** }} \\
(0.001)\end{array}$ \\
\hline Tenure* TC & $\begin{array}{l}-0.006 \text { ** } \\
(0.002)\end{array}$ & $\begin{array}{l}-0.006^{* * *} \\
(0.002)\end{array}$ \\
\hline Working hours & $\begin{array}{l}0.008^{* * * * *} \\
(0.001)\end{array}$ & $\begin{array}{l}0.008^{* * * *} \\
(0.001)\end{array}$ \\
\hline Working hours* TC & $\begin{array}{l}-0.007^{* * * *} \\
(0.002)\end{array}$ & $\begin{array}{l}-0.007^{* * * *} \\
(0.002)\end{array}$ \\
\hline Other controls and interactions & yes & yes \\
\hline B. Temporary Contract & AME & AME \\
\hline Unemployment rate (std.) & $\begin{array}{l}0.015 \text { **** } \\
(0.003)\end{array}$ & $\begin{array}{l}0.012^{* * * *} \\
(0.003)\end{array}$ \\
\hline EPL permanent (std.) & & $\begin{array}{l}0.314^{* * * *} \\
(0.115)\end{array}$ \\
\hline EPL temporary (std.) & & $\begin{array}{l}-0.194^{* * * * *} \\
(0.063)\end{array}$ \\
\hline Unemployment" EPL permanent & & $\begin{array}{l}0.012^{* *} \\
(0.005)\end{array}$ \\
\hline Unemployment"EPL temporary & & $\begin{array}{l}0.009^{* * * *} \\
(0.002)\end{array}$ \\
\hline Other controls & yes & yes \\
\hline Correlation of errors ( $\rho$ ) & $\begin{array}{l}-0.049^{* * *} \\
(0.017)\end{array}$ & $\begin{array}{l}-0.049^{* * * *} \\
(0.017)\end{array}$ \\
\hline Wald test of independent equations $(\rho=0)$ & $\mathrm{Chi}^{2}(1)=9.04(p=0.002)$ & $\operatorname{Chi}^{2}(1)=8.52(p=0.003)$ \\
\hline
\end{tabular}

Notes. ${ }^{*} p<0.10,{ }^{* *} p<0.05,{ }^{* * *} p<0.01$. Robust standard errors in parentheses, clustered at the age-group-by-country level. The informal learning dependent variable is standardised. The standardised unemployment rate (at the age-group-by-country level, six years prior to the interview) is used as a selection instrument in column (1) and column (2) adds the interaction of the latter with the corresponding standardised EPL indexes for permanent and temporary employment. All the estimations include a constant term and the same control variables as reported in Table 4. The term AME denotes average marginal effects. $\mathrm{N}=25,853$.

for permanent employees, the decreases are 0.022 and 0.002 of a standard deviation.

As mentioned previously, the larger investments in informal learning of temporary workers are expected to be more beneficial earlier in the working career, when the workers probably have better prospects of gaining a permanent position. This suggests that the difference in informal learning investments between temporary and permanent workers ends gradually and will vanish at some age and after some years of tenure. Nonetheless, it is not just a young, early career effect. According to estimation (2) in Table 7, the positive ATE of temporary contracts become insignificant (at the 95\% confidence level) after the age of 46 . Similarly, the positive ATE of temporary contracts disappear after approximately 8 years of tenure (see Fig. 3). This could probably be due to workers adjusting their labour mobility expectations when they feel trapped in a temporary job with no career prospects.

If workers generally have stronger preferences for permanent contracts (Booth et al., 2002; Holmlund and Storrie, 2002), it is reasonable to think that flexible workers rationally invest more in on-the-job informal learning to increase their chances of promotion to a more stable/secure job. Thus, we could expect that employees with expectations of upward mobility in the labour market are more likely to invest in informal learning. Since we cannot directly test for this mechanism with the PIAAC data, we use data from the European Skills Survey (2014) that allow us to distinguish between temporary workers with good and poor prospects of job stability, for some additional descriptive analyses.

Estimation results using data from the European Skills Survey, ${ }^{30}$ and the application of a similar endogenous SRM that accounts for the endogeneity of selection into the type of contract, ${ }^{31}$ indicate that full-

\footnotetext{
${ }^{30}$ In this survey, the informal learning measure is a categorical variable derived from the following question: How often, if at all, does your job involve learning new things? The respondent's options were never, sometimes, usually, and always. We constructed a temporary contract dummy variable that takes the value one for fixed-term/temporary agency contracts and zero for indefinite/permanent contracts. We derive the dummy variable on the prospects of job stability from the following question: How likely or unlikely do you think it is that you will lose your job in the next two years? Please use a scale of from 0 to 10 , where 0 means very unlikely and 10 very likely. This variable takes the value of one (for a good prospect of job stability) if the answer given was below five and zero (indicating poor prospects of job stability) if the answer given was five or above.

${ }^{31}$ In this application, we also use the corresponding unemployment rate at the age-group-by-country level as the selection instrument. We use data for 2006, collected from the OECD Statistics website, seven years prior to the survey to avoid likely global crisis changes affecting the comparability of these results
} 

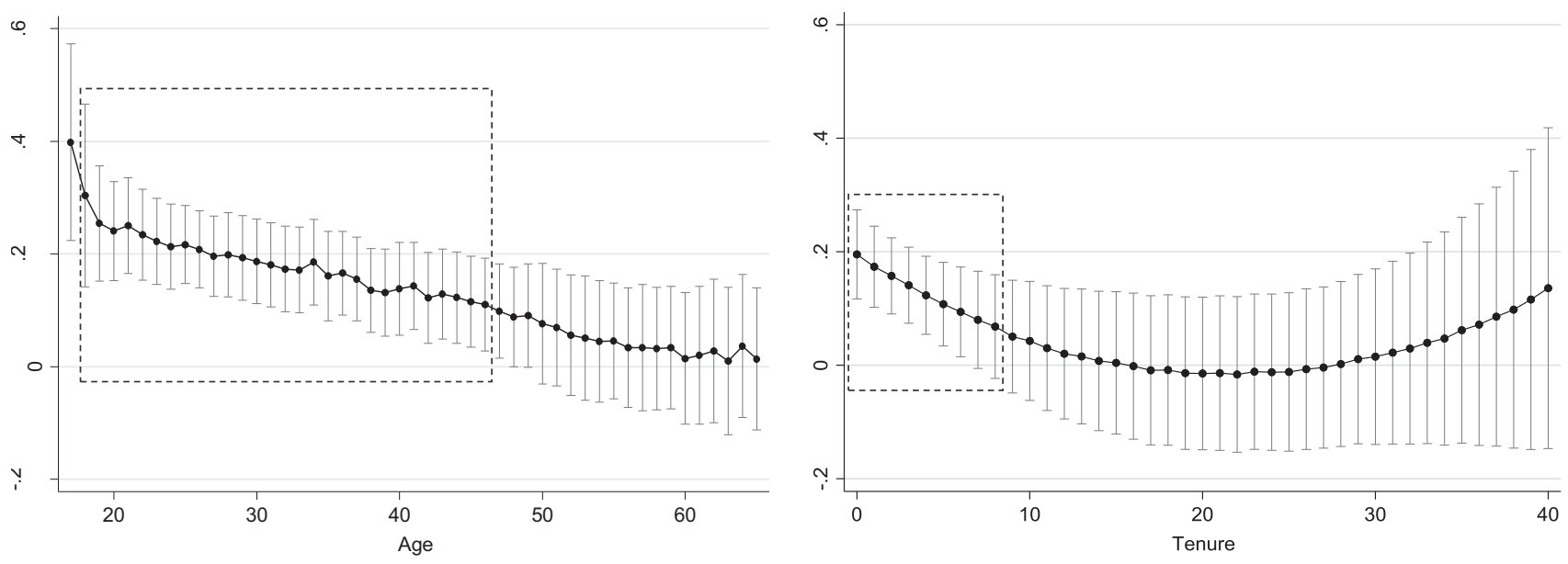

Fig. 3. Estimated ATE of temporary contracts on informal learning over age and tenure

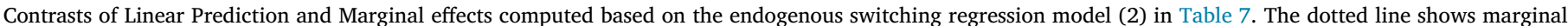
effects that are significant with $95 \%$ confidence at a minimum.

Table 8

Estimation coefficients of informal learning by type of contract, European Skills Survey 2014.

\begin{tabular}{|c|c|c|c|c|c|c|}
\hline & $\begin{array}{l}\text { OLS } \\
\text { (1) }\end{array}$ & $\begin{array}{l}\text { OProbit } \\
\text { (2) }\end{array}$ & $\begin{array}{l}\text { FIML } \\
\text { (3) }\end{array}$ & $\begin{array}{l}\text { OLS } \\
(4)\end{array}$ & $\begin{array}{l}\text { OProbit } \\
\text { (5) }\end{array}$ & $\begin{array}{l}\text { FIML } \\
\text { (6) }\end{array}$ \\
\hline \multicolumn{7}{|l|}{ A. Informal Learning } \\
\hline Temporary contract & $\begin{array}{l}0.089^{* * * *} \\
(0.020)\end{array}$ & $\begin{array}{l}0.126^{* * *} \\
(0.030)\end{array}$ & $\begin{array}{l}0.239^{* * * *} \\
(0.064)\end{array}$ & $\begin{array}{l}0.047^{*} \\
(0.027)\end{array}$ & $\begin{array}{l}0.064 \\
(0.040)\end{array}$ & $\begin{array}{l}0.166^{* *} \\
(0.067)\end{array}$ \\
\hline Good prospects of job stability & & & & $\begin{array}{l}0.015 \\
(0.017)\end{array}$ & $\begin{array}{l}0.028 \\
(0.025)\end{array}$ & $\begin{array}{l}0.023 \\
(0.023)\end{array}$ \\
\hline Temporary contract* Good prospects & & & & $\begin{array}{l}0.112^{* * * *} \\
(0.039)\end{array}$ & $\begin{array}{l}0.167^{* * * *} \\
(0.055)\end{array}$ & $\begin{array}{l}0.209^{* * * *} \\
(0.060)\end{array}$ \\
\hline Other controls & yes & yes & yes & yes & yes & yes \\
\hline B. Temporary Contract & & & $A M E$ & & & $A M E$ \\
\hline Unemployment rate (std.) & & & $\begin{array}{l}0.014^{* * * * *} \\
(0.004)\end{array}$ & & & $\begin{array}{l}0.014^{* * * *} \\
(0.004)\end{array}$ \\
\hline Other controls & & & yes & & & yes \\
\hline Correlation of errors $(\rho)$ & & & $\begin{array}{l}-0.065^{\text {** }} \\
(0.031)\end{array}$ & & & $\begin{array}{l}-0.069^{* * *} \\
(0.032)\end{array}$ \\
\hline Wald test of independent equations $(\rho=0)$ & & & $\mathrm{Chi}^{2}(1)=4.81(p=0.028)$ & & & $\mathrm{Chi}^{2}(1)=4.74(p=0.029)$ \\
\hline
\end{tabular}

Notes. ${ }^{*} p<0.10,{ }^{* *} p<0.05,{ }^{* * *} p<0.01$. Robust standard errors in parentheses, clustered at the age-group-by-country level. Data come from the European Skills Survey, conducted in 21 European countries in 2014. The sample includes full-time workers aged 24-65 not enrolled in any formal education programme. The informal learning dependent variable is ordered in four categories (0-3). Good prospects of job stability refers to a low self-reported probability of losing the job in the next two years. Other controls include age, age square, educational level, education mismatch, tenure, working hours, learning attitude, occupation, industry, firm size and country dummies. The standardised unemployment rate for 2006 (at the age-group-by-country level, collected from the OECD statistics) is used as a selection instrument in the FIML estimations (3) and (6). The term AME denotes average marginal effects. $\mathrm{N}=17,442$.

time workers with a temporary contract particularly engage more intensively in informal learning on the job than those with a permanent contract, when the temporary contract offers opportunities for future job stability. Tables 8 and 9 show the respective results. In these data, we also observe that the likelihood of job stability perceived by employees with a temporary contract decreases with the worker's age and years of tenure with the same employer.

These analyses provide further insights into the theoretical hypothesis (e.g. Weiss, 1986) that expectations of transition to permanent (more stable) employment could stimulate workers to make supplementary investments in informal learning while in a temporary job as one of the

with our main results derived from the PIAAC data. Since the informal learning information provided in this dataset has an ordered structure, we implemented an endogenous SRM that fits an ordered probit model for the dependent variable. For this purpose, we used the cmp program. For a detailed description of this command, see Roodman (2011). mechanisms driving our main findings. We discuss this issue more in detail in Section 6 .

\subsubsection{Heterogeneous jobs}

Our main estimates could also differ if firms select workers into temporary versus permanent contracts because of the task content of different jobs, which could lead to heterogeneity in informal learning opportunities. For instance, it could be that high-skilled jobs or jobs that entail more task flexibility and problem-solving tasks are less likely to be selected for temporary contracts ${ }^{32}$ and, at the same time, offer more informal learning opportunities. To test for this heterogeneity, we include different job-content characteristics and estimate heterogeneous effects in our interacted endogenous SRM.

First, we do not find any evidence that informal learning intensity differs between high-skilled and low-skilled temporary jobs, although

\footnotetext{
32 Descriptive statistics are provided in Table A3 in the Appendix.
} 
Table 9

AME of temporary contracts on informal learning, European Skills Survey 2014.

\begin{tabular}{lllll}
\hline Informal learning & Never & Sometimes & Usually & Always \\
\hline $\begin{array}{c}\text { Temporary contract (Perm. contract ref.) } \\
\text { With good prospects }\end{array}$ & $-0.007^{* *}$ & $-0.048^{* *}$ & $0.016^{* * *}$ & $0.039^{* *}$ \\
of job stability & $(0.003)$ & $(0.021)$ & $(0.006)$ & $(0.018)$ \\
$\quad \begin{array}{l}\text { With poor prospects } \\
\text { of job stability }\end{array}$ & $-0.015^{* * * *}$ & $-0.123^{* * *}$ & $0.028^{* * *}$ & $0.110^{* * *}$ \\
\hline
\end{tabular}

Notes. ${ }^{*} p<0.10,{ }^{* *} p<0.05,{ }^{* * *} p<0.01$. Robust standard errors in parentheses, clustered at the age-group-by-country level. This table shows average marginal effects (AMEs) computed on the FIML specification (6) of Table 8. The dependent variable informal learning is measured by four ordinal categories as shown in the four columns. The AME for categorical variables is the discrete change from the base level. $\mathrm{N}=17,442$.

those employed in high-skilled jobs are significantly less likely to be selected into temporary contracts and simultaneously tend to engage more intensively in learning on the job. ${ }^{33}$ Second, by using the information on task-content of jobs as provided by the PIAAC survey, we are able to test for further heterogeneity. Table 10 shows that jobs that involve greater task flexibility, and more planning, literacy-related tasks and ICT-related tasks are less likely to be filled with individuals employed on a temporary basis. The contrary occurs with jobs that more often involve physical tasks, while task collaboration and teamwork and problemsolving and numeracy-related tasks do not seem to have a significant influence in job contract type selection. At the same time, Table 10 shows that employees tend to engage more intensively in informal learning when they are employed in jobs with higher levels of task flexibility and teamwork and problem-solving, planning, numeracy-, literacy- and ICT-related tasks. Conversely, jobs with more physical-task content seem to offer fewer informal learning opportunities. More interestingly, the interaction coefficients suggest no significant differences between temporary and permanent workers regarding the above results, the only exception being the larger positive effect on informal learning that task collaboration and teamwork has for temporary employees, which suggests that interaction with peers particularly enhances on-the-job informal learning of temporary workers. When including all these tasks characteristics, we still find the positive influence of temporary contracts on informal learning.

\subsubsection{Heterogeneous effects from unobservable characteristics (MTEs)}

There are reasons to expect further unobservable heterogeneity in the informal learning outcomes of employees with a temporary contract. Since workers differ, for instance, in their ability, personality traits, and the information and expectations they have about their future career when starting a job, individuals with different unobservable characteristics could respond differently to a temporary contract. Heterogeneity could also result from variety in the quality of temporary contracts, for example, regarding the chances of these being converted into permanent contracts.

To investigate this heterogeneity, we estimate MTEs (at the mean value of all covariates in $X$ ) along the 99 percentile points of the distribution of unobservables $U_{D}$, computed on an endogenous SRM of informal learning similar to specification (5) of Table 4 but allowing different correlation parameters $\rho$ and variance $\sigma^{2}$ between permanent and temporary workers, as explained in Section 3 . The corresponding results are shown in Fig. 4 and Table A4 in the Appendix A. When allowing for this heterogeneity, our main findings hold. The model fits well and, in fact, the estimated ATE increases from 0.22 to 0.28 of a standard deviation in comparison with our results in Table 4.

The MTE estimates describe whether informal learning outcomes for workers on the margin of a temporary job placement increase or de-

\footnotetext{
33 The interaction term between temporary contracts and high-skilled occupations is not significant with $90 \%$ of confidence. Results are available upon request.
}

crease with the probability of being selected into a temporary contract, $p_{i}\left(Z_{i}\right)$, conditioned on marginal changes in the instrument. The MTEs then show if and to what extent the investments in informal learning of employees change if they are shifted into a temporary contract by marginally increasing the corresponding unemployment rate.

Following Heckman and Vytlacil (2005), in Fig. 4 the MTEs of low $U_{D}$ values show the expected effects in the informal learning of workers who are more likely, due to unobserved reasons, to be selected into temporary contracts, that is, those who would be selected even if the unemployment rate was rather small. High $U_{D}$ values in Fig. 4 therefore represent workers with higher probabilities of being selected into a permanent contract, which means that the unemployment rate would have to be very large to induce them to be in a temporary job. The upward-sloping shape of the MTE curve in $U_{D}$ in Fig. 4 then indicates that the ATE of temporary contracts is higher for employees who are more likely to be selected in permanent jobs (high $U_{D}$ ), which means that the lower the likelihood of selection into a temporary contract, the higher the informal learning investments of workers are expected to be if they were in a temporary rather than in a permanent job. ${ }^{34}$ This increase in the MTEs at the upper levels of $U_{D}$ also suggests that workers on the margin of a temporary job under the highest unemployment rates are likely to have better unobserved characteristics (such as ability and motivation) and thus would invest the most in learning on the job in comparison with their counterparts in permanent jobs. This result could be because these individuals know their odds of obtaining a more stable position, given their own characteristics, and could be more able to make informed choices of investing (or signalling) in learning to improve those possibilities. These MTE results provide more insight into the main mechanism we propose for our findings, that is, that employees in temporary contracts who have better prospects for their future career would rationally invest more in on-the-job informal learning to increase their chances of promotion to a permanent job.

\section{Conclusions and discussion}

We have analysed the difference in informal learning at work between temporary and permanent male employees across 20 OECD countries. Human capital theory predicts that both firms and employees are less willing to invest in skills if workers are hired under temporary contracts. Remarkably, we find that workers in temporary jobs engage more intensively in informal learning than permanent employees do, although the former are, indeed, less likely to participate in formal training.

We conclude that the difference in the intensity of on-the-job informal learning between workers with temporary and permanent contracts

\footnotetext{
34 The increasing MTE curve also indicates negative selection in unobserved characteristics, in line with our hypotheses in Section 3. This negative selection is also suggested if $\rho_{1}>\rho_{0}$ (Cornelissen et al., 2016), as shown in Table A6 in the Appendix.
} 
Table 10

Heterogeneous effects of temporary contracts by job content characteristics.

\begin{tabular}{|c|c|c|}
\hline & FIML (1) & FIML (2) \\
\hline \multicolumn{3}{|l|}{ A. Informal Learning } \\
\hline \multirow[t]{2}{*}{ ATE } & $0.245^{* * * *}$ & $0.244^{\text {*水水 }}$ \\
\hline & $(0.044)$ & $(0.045)$ \\
\hline \multirow[t]{2}{*}{ ATT } & $0.261^{* * * *}$ & $0.260^{* * * *}$ \\
\hline & $(0.045)$ & $(0.046)$ \\
\hline \multirow[t]{2}{*}{ Task flexibility } & $0.015^{\text {*** }}$ & $0.015^{* *}$ \\
\hline & $(0.007)$ & $(0.007)$ \\
\hline \multirow[t]{2}{*}{ Task flexibility* TC } & -0.001 & -0.001 \\
\hline & $(0.022)$ & $(0.022)$ \\
\hline \multirow[t]{2}{*}{ Task collaboration - teamwork } & $0.166^{\text {**** }}$ & $0.166^{* * *}$ \\
\hline & $(0.009)$ & $(0.009)$ \\
\hline \multirow[t]{2}{*}{ Task collaboration - teamwork* TC } & $0.049^{* *}$ & $0.049^{* * *}$ \\
\hline & $(0.020)$ & $(0.020)$ \\
\hline \multirow[t]{2}{*}{ Problem-solving tasks } & $0.136^{* * *}$ & $0.136^{* * *}$ \\
\hline & $(0.008)$ & $(0.008)$ \\
\hline \multirow[t]{2}{*}{ Problem-solving tasks* TC } & 0.004 & 0.004 \\
\hline & $(0.020)$ & $(0.020)$ \\
\hline \multirow[t]{2}{*}{ Planning tasks } & $0.029^{* * * * *}$ & $0.029^{* * * *}$ \\
\hline & $(0.007)$ & $(0.007)$ \\
\hline \multirow[t]{2}{*}{ Planning tasks* TC } & -0.025 & -0.025 \\
\hline & $(0.020)$ & $(0.020)$ \\
\hline \multirow[t]{2}{*}{ Physical tasks } & 0.007 & 0.007 \\
\hline & $(0.008)$ & $(0.008)$ \\
\hline \multirow[t]{2}{*}{ Physical tasks* TC } & -0.012 & -0.012 \\
\hline & $(0.021)$ & $(0.021)$ \\
\hline Numeracy-related tasks & $0.031^{\text {***** }}$ & $0.031^{* * * * *}$ \\
\hline & $(0.010)$ & $(0.010)$ \\
\hline Numeracy-related tasks* TC & -0.003 & -0.003 \\
\hline & $(0.025)$ & $(0.025)$ \\
\hline Literacy-related tasks & $0.151^{* * * * *}$ & $0.151^{* * * *}$ \\
\hline & $(0.011)$ & $(0.011)$ \\
\hline Literacy-related tasks* TC & -0.034 & -0.034 \\
\hline & $(0.032)$ & $(0.032)$ \\
\hline ICT-related tasks & $0.048^{\text {***** }}$ & $0.048^{* * * *}$ \\
\hline & $(0.012)$ & $(0.012)$ \\
\hline ICT-related tasks* TC & 0.006 & 0.006 \\
\hline & $(0.030)$ & $(0.030)$ \\
\hline Other controls & yes & yes \\
\hline B. Temporary Contract & $A M E$ & $A M E$ \\
\hline Unemployment rate (std.) & $0.015^{\text {**** }}$ & $0.011^{* * *}$ \\
\hline & $(0.003)$ & $(0.003)$ \\
\hline EPL permanent (std.) & & $0.249^{* *}$ \\
\hline & & $(0.012)$ \\
\hline EPL temporary (std.) & & $-0.160^{* *}$ \\
\hline & & $(0.071)$ \\
\hline Unemployment*EPL permanent & & $0.011^{* *}$ \\
\hline & & $(0.005)$ \\
\hline Unemployment*EPL temporary & & $0.007^{* *}$ \\
\hline & & $(0.003)$ \\
\hline Task flexibility & $-0.005^{* *}$ & $-0.005^{* *}$ \\
\hline & $(0.002)$ & $(0.002)$ \\
\hline Task collaboration and teamwork & 0.003 & 0.003 \\
\hline & $(0.002)$ & $(0.002)$ \\
\hline Problem-solving tasks & -0.001 & -0.001 \\
\hline & $(0.003)$ & $(0.003)$ \\
\hline Planning tasks & $-0.007^{\text {**** }}$ & $-0.007^{* * * *}$ \\
\hline & $(0.002)$ & $(0.002)$ \\
\hline Physical tasks & 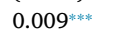 & $0.009^{* * * * *}$ \\
\hline & $(0.003)$ & $(0.003)$ \\
\hline Numeracy-related tasks & 0.000 & 0.000 \\
\hline & $(0.003)$ & $(0.003)$ \\
\hline Literacy- related tasks & $-0.009^{* *}$ & $-0.009^{* *}$ \\
\hline & $(0.004)$ & $(0.004)$ \\
\hline ICT-related tasks & $-0.015^{\text {**** }}$ & $-0.015^{* * * * *}$ \\
\hline & $(0.004)$ & $(0.004)$ \\
\hline Other controls & yes & yes \\
\hline Correlation of errors $(\rho)$ & $-0.095^{\text {**** }}$ & $-0.094^{* * * *}$ \\
\hline & $(0.027)$ & $(0.027)$ \\
\hline
\end{tabular}


Table 10 (continued)

\begin{tabular}{lll}
\hline & FIML (1) & FIML (2) \\
\hline $\begin{array}{l}\text { Wald test of independent } \\
\text { equations }(\rho=0)\end{array}$ & $\begin{array}{l}\mathrm{Chi}^{2}(1)=12.5 \\
(p=0.000)\end{array}$ & $\begin{array}{l}\mathrm{Chi}^{2}(1)=12.1 \\
(p=0.001)\end{array}$ \\
\hline
\end{tabular}

Notes. ${ }^{*} p<0.10,{ }^{* *} p<0.05,{ }^{* * *} p<0.01$. Robust standard errors in parentheses, clustered at the agegroup-by-country level. The informal learning dependent variable is standardised. The standardised unemployment rate (at the age-group-by-country level, six years prior to the interview) is used as a selection instrument in column (1) and column (2) adds the interaction of the latter with the corresponding standardised EPL indexes for permanent and temporary employment. All the estimations include a constant term and the same control variables as reported in Table 4. The term AME denotes average marginal effects. $\mathrm{N}=23,069$.

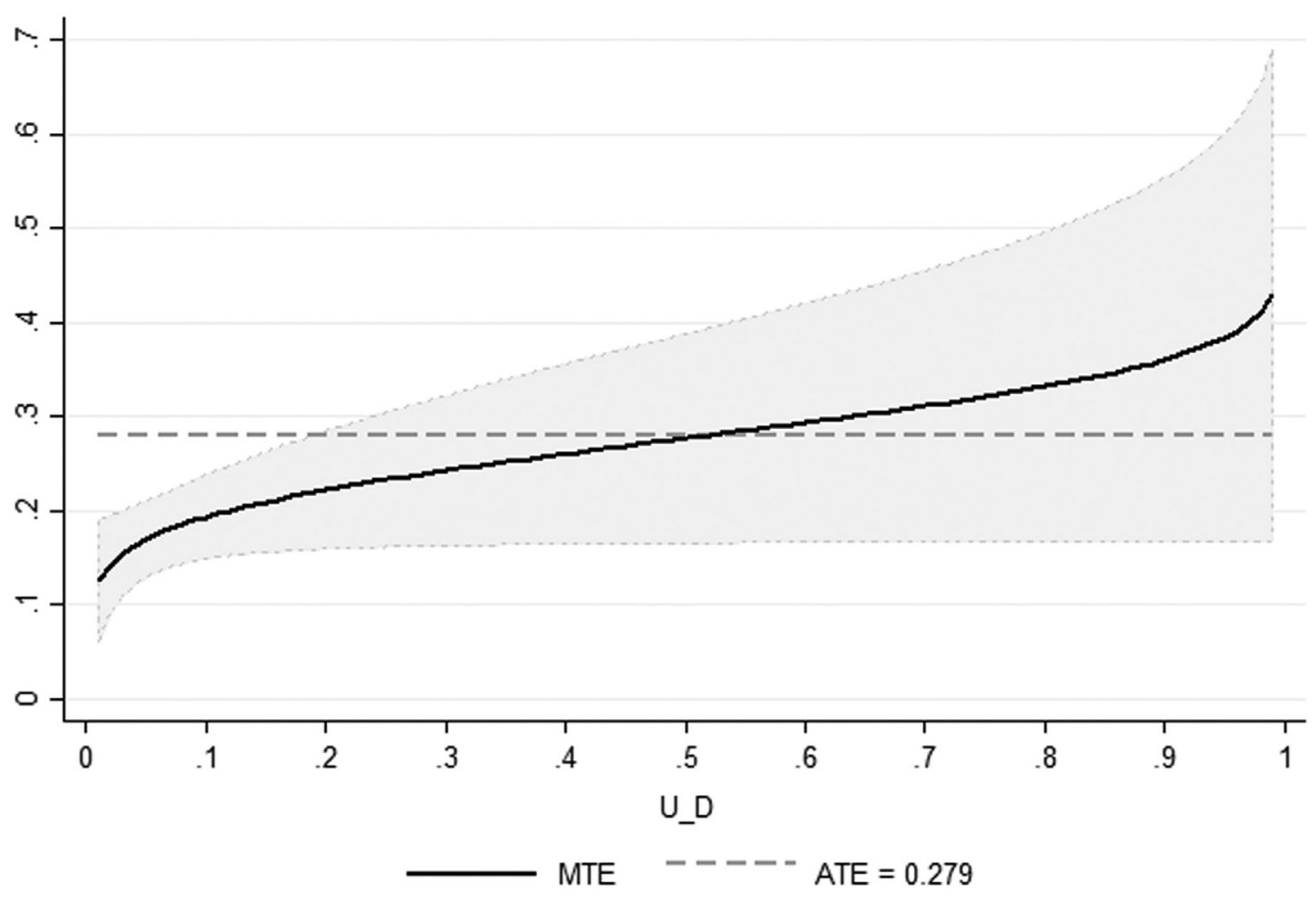

Fig. 4. Estimated MTE of temporary contracts on informal learning.

is positive and between 0.22 and 0.28 of a standard deviation. ${ }^{35}$ These results account for the endogeneity of the selection into temporary contracts by estimating FIML endogenous switching regression models that exploit workers' differential exposure to unemployment and employment protection legislation across countries and age groups.

Our findings could be driven by several mechanisms. Although the PIAAC data do not allow us to assess the particular mechanism behind our main results, we can discard some of the possible explanations and provide further insights on these relevant mechanisms.

First, the hypothesis that temporary workers could substitute informal learning for the lack of formal training is not supported by our analysis. Instead, we find complementarity between these two types of learning, which is consistent with the idea that human capital accumulated through training not only provides workers with higher skills but could also increase their informal learning capacity (Rosen, 1972).

Second, we do not find support for the view that high-skilled workers drive the difference in informal learning between temporary and permanent male employees. Although we find that particularly peer in-

\footnotetext{
35 This difference is substantial if we consider that having a temporary contract has a similar impact on informal learning as approximately 10 years of schooling.
}

teraction enhances the intensity of informal learning among temporary employees, their difference in informal learning in comparison with permanent workers is not driven by heterogeneity in the task content of temporary jobs.

However, the higher informal learning investments of temporary employees might be driven by the incentives of finding a more stable job. If workers generally prefer permanent contracts (Booth et al., 2002; Holmlund and Storrie, 2002), it is reasonable to think that those in temporary jobs could have stronger incentives to invest in on-the-job learning to increase their chances of promotion to a more secure job. ${ }^{36}$ In line with this hypothesis, we find that the positive influence of temporary contracts is larger earlier in workers' careers, when workers generally have better prospects of transition to permanent employment than later in their career. Additional descriptive results from the European Skills Survey that allow us to distinguish between temporary workers with and without prospects of job stability in the near future, suggest that the intensity of informal learning is likely higher for temporary workers who have better expectations of job stability. These results are consistent with our MTE analysis when using the PIAAC dataset, which shows that

\footnotetext{
${ }^{36}$ This could be incentivised by the lower opportunity costs of informal learning in contrast to training (Destré et al., 2008).
} 
the expected effects in informal learning are significantly higher among workers with a temporary contract who are more likely to be selected into permanent contracts due to their unobservable characteristics. This finding suggests that those who know about their better chances of obtaining a permanent job position, given their own characteristics, are those expected to show a higher intensity of informal learning at work, which could help to improve these chances in their favour.

This analysis suggests that workers may perceive more intense learning as a profitable investment in their career development, particularly when facing the uncertainty of a temporary contract. As explained by Weiss (1986), the possibility of shifting to a better job affects the returns to human capital and, therefore, increases the incentives for supplementary investments in learning activities while working. Furthermore, if these investments are positively affected by a lower discount rate because future perspectives become more important, incentives for selfinvestment increase and give rise to human capital accumulation until a more stable job is obtained.

Our findings could then be likely driven by the mechanism suggested in the literature on the stepping-stone effects of temporary employment. Most of these studies evoke the idea that the odds of transition from temporary to permanent jobs likely increase with investments in on-the-job learning and the improvement of skills while gaining work experience (e.g. Autor, 2001; Booth et al., 2002; Gagliarducci, 2005; De Graaf-Zij1 et al., 2011; Cockx and Picchio, 2012). This implies that, if human capital investments on the job decline over the lifecycle by a search for a better job, accepting a temporary job that might pay less initially but involves higher learning potential can be a good strategy for workers in their early careers, since such jobs are more likely to have a steppingstone effect (Sicherman and Galor, 1990; Heckman et al., 2002).

The implicit stepping-stone incentive of temporary jobs as a plausible explanation for our results also relates to the literature on job matching and screening. If firms use temporary contracts to select the best workers for permanent positions, human capital acquired through learning on the job becomes an important source for firms to investigate the quality of the match and productivity of potential permanent employees (Autor, 2001; Nagypál, 2007; Faccini, 2014). Temporary contracts could then also increase workers' incentives to signal positively their skills and productivity by accumulating more job-specific expertise through onthe-job learning.

Our analyses point towards a potential positive feature of temporary contracts that has important implications. Temporary jobs need not be dead-end jobs. If temporary jobs are taken by individuals in lieu of un- employment in search for further individual promotion in the labour market, these jobs could offer them opportunities for learning by doing particular tasks and productive interaction with other workers. This is important not only as a source of productive accumulation of human capital while working but also as a potential advantage for individuals who would otherwise be unemployed. Such jobs with high learning content might then be a stepping stone towards more stable employment.

The challenge of harnessing the learning potential of temporary employment also implies the reduction of the training participation penalty induced by the short duration of contracts. This penalty might not only contribute to disparities in the labour market but, as we show, could also compromise the benefits of the complementarity between formal training and informal learning. Our complementarity analysis suggests two different kinds of temporary jobs in terms of their learning opportunities: (1) good temporary jobs, with high levels of task autonomy and collaboration, more teamwork and problem-solving tasks, offering good opportunities for training and informal learning and, likely, leading to positive career expectations of upward mobility, and (2) bad temporary jobs, which have no or very few opportunities to foster workers' human capital. In the latter jobs, workers could get trapped in a cycle between precarious jobs and unemployment. Thus, our study suggests that labour segmentation occurs not only between permanent and temporary jobs but also within temporary employment due to the distinction between temporary jobs of low and high learning content.

Policy makers have already stressed the importance of finding 'an appropriate balance between flexibility and security' to prevent part of the labour force from becoming trapped in dead-end jobs (so-called flexicurity agenda, European Commission, 2007). Access to opportunities for workers' human capital development remains a crucial issue for many governments to create such a balance. These policies should therefore be supported by analysing how contract incentives influence workers' skill investments and their career development expectations. The design of these policies underlines the importance of improving firms' learning strategies to optimise the benefits of both training and informal learning as a means of fostering not only successful transitions and the sustainable employability of a flexible workforce but also the aggregate productive capacity of the economy in the long term. In this respect, it is important that further longitudinal research would aim to identify the causal effects of both formal training and informal learning on workers' transition from temporary to permanent jobs.

\section{Appendix A. Additional analyses}

Tables A3 and A4. 
Table A1

Training participation of the unemployed.

\begin{tabular}{lllll}
\hline Probit & $\begin{array}{l}\text { Job-related training (1) } \\
A M E\end{array}$ & $\begin{array}{l}\text { Job-related training (2) } \\
A M E\end{array}$ & $\begin{array}{l}\text { Any type of training (3) } \\
A M E\end{array}$ & $\begin{array}{l}\text { Any type of training (4) } \\
A M E\end{array}$ \\
\hline Unemployment & -0.002 & 0.009 & 0.003 & 0.010 \\
rate $t$ & $(0.016)$ & $(0.018)$ & $(0.017)$ & $(0.018)$ \\
Years of & & $0.015^{* * *}$ & $0.016^{* * * *}$ \\
education & $(0.003)$ & $(0.003)$ \\
Learning attitude & $0.033^{* * *}$ & $0.033^{* * *}$ \\
Numeracy skills & & $(0.008)$ & $(0.008)$ \\
& $0.001^{* *}$ & & $0.001^{* * *}$ \\
Other controls & yes & $(0.000)$ & yes & $(0.000)$ \\
$N$ & 3209 & yes & 3348 & yes \\
\hline
\end{tabular}

Notes. ${ }^{*} p<0.10,{ }^{* *} p<0.05,{ }^{* * *} p<0.01$. The dependent variable is the dummy of participation in training. Unemployment rate $t$ is the standardised unemployment rate (at the age-group-by-country level, same year of the interview) is the independent variable. Other controls include age and country-fixed effects. The term AME denotes average marginal effects.

Table A2

Estimations of informal learning intensity (sensitivity tests).

\begin{tabular}{|c|c|c|c|c|c|c|}
\hline & ATE (1) & $\rho$ & Wald test $\rho=0 \mathrm{Chi}^{2}(1)$ & ATE (2) & $\rho$ & Wald test $\rho=0 \mathrm{Chi}^{2}(1)$ \\
\hline \multicolumn{7}{|l|}{$\underline{\text { Panel A. Probit specifications excluding }}$} \\
\hline Overeducated and undereducated & $\begin{array}{l}0.179 * * * \\
(0.045)\end{array}$ & $\begin{array}{l}-0.062^{\text {**** }} \\
(0.023)\end{array}$ & $\begin{array}{l}7.33 \\
(p=0.007)\end{array}$ & $\begin{array}{l}0.177^{\text {***** }} \\
(0.045)\end{array}$ & $\begin{array}{l}-0.061^{\text {**** }} \\
(0.023)\end{array}$ & $\begin{array}{l}7.11 \\
(p=0.008)\end{array}$ \\
\hline Learning attitude & $\begin{array}{l}0.181^{* * * *} \\
(0.045)\end{array}$ & $\begin{array}{l}-0.062^{\text {**** }} \\
(0.023)\end{array}$ & $\begin{array}{l}7.30 \\
(p=0.007)\end{array}$ & $\begin{array}{l}0.181^{\text {**** }} \\
(0.045)\end{array}$ & $\begin{array}{l}-0.061^{\text {**** }} \\
(0.023)\end{array}$ & $\begin{array}{l}7.08 \\
(p=0.008)\end{array}$ \\
\hline Numeracy skills & $\begin{array}{l}0.184^{* * * *} \\
(0.047)\end{array}$ & $\begin{array}{l}-0.066 \text { *** } \\
(0.024)\end{array}$ & $\begin{array}{l}7.37 \\
(p=0.007)\end{array}$ & $\begin{array}{l}0.181^{\text {****** }} \\
(0.047)\end{array}$ & $\begin{array}{l}-0.065^{\text {**** }} \\
(0.024)\end{array}$ & $\begin{array}{l}7.20 \\
(p=0.007)\end{array}$ \\
\hline Tenure & $\begin{array}{l}0.189^{* * * *} \\
(0.042)\end{array}$ & $\begin{array}{l}-0.053^{* * * *} \\
(0.020)\end{array}$ & $\begin{array}{l}6.91 \\
(p=0.009)\end{array}$ & $\begin{array}{l}0.187^{* * * *} \\
(0.042)\end{array}$ & $\begin{array}{l}-0.053^{\text {**** }} \\
(0.020)\end{array}$ & $\begin{array}{l}6.82 \\
(p=0.009)\end{array}$ \\
\hline Working hours & $\begin{array}{l}0.175^{* * * *} \\
(0.045)\end{array}$ & $\begin{array}{l}-0.059^{\text {**** }} \\
(0.023)\end{array}$ & $\begin{array}{l}6.35 \\
(p=0.012)\end{array}$ & $\begin{array}{l}0.172^{\text {**** }} \\
(0.045)\end{array}$ & $\begin{array}{l}-0.057^{\text {***** }} \\
(0.023)\end{array}$ & $\begin{array}{l}6.08 \\
(p=0.014)\end{array}$ \\
\hline Occupation & $\begin{array}{l}0.179 * * * * \\
(0.045)\end{array}$ & $\begin{array}{l}-0.059^{\text {**** }} \\
(0.023)\end{array}$ & $\begin{array}{l}6.25 \\
(p=0.012)\end{array}$ & $\begin{array}{l}0.176^{* * * * *} \\
(0.045)\end{array}$ & $\begin{array}{l}-0.057^{\text {**** }} \\
(0.023)\end{array}$ & $\begin{array}{l}5.81 \\
(p=0.016)\end{array}$ \\
\hline Industry & $\begin{array}{l}0.174 \text { **** } \\
(0.045)\end{array}$ & $\begin{array}{l}-0.060^{\text {**** }} \\
(0.023)\end{array}$ & $\begin{array}{l}6.75 \\
(p=0.009)\end{array}$ & $\begin{array}{l}0.176^{\text {***** }} \\
(0.045)\end{array}$ & $\begin{array}{l}-0.061^{\text {***** }} \\
(0.023)\end{array}$ & $\begin{array}{l}6.90 \\
(p=0.009)\end{array}$ \\
\hline Firm size & $\begin{array}{l}0.182^{* * *} \\
(0.045)\end{array}$ & $\begin{array}{l}-0.062^{* * *} \\
(0.022)\end{array}$ & $\begin{array}{l}7.52 \\
(p=0.006)\end{array}$ & $\begin{array}{l}0.180^{* * * *} \\
(0.045)\end{array}$ & $\begin{array}{l}-0.062 \text { *** } \\
(0.022)\end{array}$ & $\begin{array}{l}7.71 \\
(p=0.006)\end{array}$ \\
\hline Occupation, industry and firm size & $\begin{array}{l}0.178^{* * * *} \\
(0.046)\end{array}$ & $\begin{array}{l}-0.062^{\text {**** }} \\
(0.023)\end{array}$ & $\begin{array}{l}7.11 \\
(p=0.008)\end{array}$ & $\begin{array}{l}0.175^{\text {***** }} \\
(0.046)\end{array}$ & $\begin{array}{l}-0.061^{\text {***** }} \\
(0.023)\end{array}$ & $\begin{array}{l}6.82 \\
(p=0.009)\end{array}$ \\
\hline Country fixed effects & $\begin{array}{l}0.282^{\text {**** }} \\
(0.049)\end{array}$ & $\begin{array}{l}-0.122^{* * *} \\
(0.025)\end{array}$ & $\begin{array}{l}23.5 \\
(p=0.000)\end{array}$ & 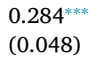 & $\begin{array}{l}-0.124^{* * * *} \\
(0.025)\end{array}$ & $\begin{array}{l}25.1 \\
(p=0.000)\end{array}$ \\
\hline \multicolumn{7}{|l|}{ Panel B. Adding controls } \\
\hline $\begin{array}{l}\text { Year of interview and country } \\
N=26,495\end{array}$ & $\begin{array}{l}0.394^{* * * *} \\
(0.058)\end{array}$ & $\begin{array}{l}-0.168^{* * * *} \\
(0.028)\end{array}$ & $\begin{array}{l}36.5 \\
(p=0.000)\end{array}$ & $\begin{array}{l}0.393^{* * * *} \\
(0.045)\end{array}$ & $\begin{array}{l}-0.167^{* * * *} \\
(0.028)\end{array}$ & $\begin{array}{l}35.6 \\
(p=0.000)\end{array}$ \\
\hline $\begin{array}{l}\text { Age, age }{ }^{2} \text { and years of education } \\
\mathrm{N}=26,338\end{array}$ & $\begin{array}{l}0.145^{* * *} \\
(0.051)\end{array}$ & $\begin{array}{l}-0.044^{* *} \\
(0.021)\end{array}$ & $\begin{array}{l}4.38 \\
(p=0.036)\end{array}$ & $\begin{array}{l}0.143^{\text {***** }} \\
(0.050)\end{array}$ & $\begin{array}{l}-0.042^{* *} \\
(0.021)\end{array}$ & $\begin{array}{l}4.31 \\
(p=0.038)\end{array}$ \\
\hline $\begin{array}{l}\text { Learning attitude and numeracy skills } \\
\qquad \mathrm{N}=26,315\end{array}$ & $\begin{array}{l}0.154 * * * * \\
(0.044)\end{array}$ & $\begin{array}{l}-0.052^{\text {***** }} \\
(0.020)\end{array}$ & $\begin{array}{l}6.78 \\
(p=0.010)\end{array}$ & $\begin{array}{l}0.151^{* * * *} \\
(0.044)\end{array}$ & $\begin{array}{l}-0.051^{* *} \\
(0.020)\end{array}$ & $\begin{array}{l}6.46 \\
(p=0.011)\end{array}$ \\
\hline $\begin{array}{l}\text { Overeducated and undereducated } \\
\qquad \mathrm{N}=26,315\end{array}$ & $\begin{array}{l}0.158^{* * * *} \\
(0.044)\end{array}$ & $\begin{array}{l}-0.050^{* *} \\
(0.020)\end{array}$ & $\begin{array}{l}6.06 \\
(p=0.014)\end{array}$ & $\begin{array}{l}0.156^{* * * *} \\
(0.044)\end{array}$ & $\begin{array}{l}-0.049^{* *} \\
(0.020)\end{array}$ & $\begin{array}{l}5.80 \\
(p=0.016)\end{array}$ \\
\hline Occupation & $0.176^{* * * *}$ & $-0.049^{* *}$ & 6.33 & $0.174^{* * * *}$ & $-0.048^{* *}$ & 6.25 \\
\hline $\mathrm{N}=25,966$ & $(0.041)$ & $(0.020)$ & $(p=0.012)$ & $(0.041)$ & $(0.020)$ & $(p=0.012)$ \\
\hline Industry and firm size & $0.192^{* * * *}$ & $-0.053^{* * * *}$ & 6.85 & $0.190^{* * * * *}$ & $-0.052^{* * * *}$ & 6.65 \\
\hline $\mathrm{N}=25,853$ & $(0.043)$ & $(0.020)$ & $(p=0.009)$ & $(0.043)$ & $(0.020)$ & $(p=0.010)$ \\
\hline $\begin{array}{l}\text { Tenure and working hours } \\
\mathrm{N}=25,853\end{array}$ & $\begin{array}{l}0.223^{* * *} \\
(0.045)\end{array}$ & $\begin{array}{l}-0.085^{* * * *} \\
(0.023)\end{array}$ & $\begin{array}{l}14.1 \\
(p=0.000)\end{array}$ & $\begin{array}{l}0.221^{\text {***** }} \\
(0.045)\end{array}$ & $\begin{array}{l}-0.085^{* * * *} \\
(0.023)\end{array}$ & $\begin{array}{l}14.0 \\
(p=0.000)\end{array}$ \\
\hline \multicolumn{7}{|l|}{ Panel C. Alternative specifications } \\
\hline $\begin{array}{l}\text { Age variable in 5-year categories } \\
\mathrm{N}=25,853\end{array}$ & $\begin{array}{l}0.208^{* * * *} \\
(0.046)\end{array}$ & $\begin{array}{l}-0.074^{* * * *} \\
(0.023)\end{array}$ & $\begin{array}{l}9.90 \\
(p=0.002)\end{array}$ & $\begin{array}{l}0.206^{* * * * *} \\
(0.046)\end{array}$ & $\begin{array}{l}-0.073^{* * * *} \\
(0.023)\end{array}$ & $\begin{array}{l}9.70 \\
(p=0.002)\end{array}$ \\
\hline $\begin{array}{l}\text { Including tenure square term } \\
\qquad \mathrm{N}=25,853\end{array}$ & $\begin{array}{l}0.212^{* * *} \\
(0.040)\end{array}$ & $\begin{array}{l}-0.101^{* * * *} \\
(0.020)\end{array}$ & $\begin{array}{l}23.8 \\
(p=0.000)\end{array}$ & $\begin{array}{l}0.213^{* * * * *} \\
(0.040)\end{array}$ & $\begin{array}{l}-0.101^{* * *} \\
(0.020)\end{array}$ & $\begin{array}{l}24.2 \\
(p=0.000)\end{array}$ \\
\hline \multicolumn{7}{|l|}{ Panel D. Restricted samples } \\
\hline $\begin{array}{l}\text { Unemployment rate }<=0.2 \\
\quad \mathrm{~N}=25,249\end{array}$ & $\begin{array}{l}0.190^{* * * *} \\
(0.045)\end{array}$ & $\begin{array}{l}-0.066^{* * * *} \\
(0.023)\end{array}$ & $\begin{array}{l}7.16 \\
(p=0.007)\end{array}$ & $\begin{array}{l}0.188^{\text {***** }} \\
(0.045)\end{array}$ & $\begin{array}{l}-0.066^{* * * * *} \\
(0.023)\end{array}$ & $\begin{array}{l}6.96 \\
(p=0.008)\end{array}$ \\
\hline $\begin{array}{l}\text { Unemployment rate }<=0.1 \\
\qquad \mathrm{~N}=20,986\end{array}$ & $\begin{array}{l}0.178^{* * *} \\
(0.048)\end{array}$ & $\begin{array}{l}-0.054 * \\
(0.024)\end{array}$ & $\begin{array}{l}5.14 \\
(p=0.023)\end{array}$ & $\begin{array}{l}0.175^{* * * * *} \\
(0.048)\end{array}$ & $\begin{array}{l}-0.054 * * \\
(0.024)\end{array}$ & $\begin{array}{l}4.98 \\
(p=0.026)\end{array}$ \\
\hline
\end{tabular}


Table A2 (continued)

\begin{tabular}{|c|c|c|c|c|c|c|}
\hline & ATE (1) & $\rho$ & Wald test $\rho=0 \mathrm{Chi}^{2}(1)$ & ATE (2) & $\rho$ & Wald test $\rho=0 \mathrm{Chi}^{2}(1)$ \\
\hline Training sample & $0.217^{\text {**** }}$ & $-0.082^{* * * *}$ & 13.5 & $0.214^{* * * *}$ & $-0.081^{* * *}$ & 13.1 \\
\hline $\mathrm{N}=22,232$ & $(0.044)$ & $(0.022)$ & $(p=0.000)$ & $(0.044)$ & $(0.022)$ & $(p=0.000)$ \\
\hline Excl. non-EU countries & $0.280^{\text {***** }}$ & $-0.096^{* * * *}$ & 19.0 & $0.279^{* * * *}$ & $-0.096^{* * *}$ & 18.7 \\
\hline $\mathrm{N}=21,989$ & $(0.042)$ & $(0.022)$ & $(p=0.000)$ & $(0.042)$ & $(0.022)$ & $(p=0.000)$ \\
\hline Excl. Poland and Korea & $0.238^{* * * *}$ & $-0.084^{* * * * *}$ & 10.8 & $0.237^{* * * *}$ & $-0.084^{* * *}$ & 10.8 \\
\hline $\mathrm{N}=23,153$ & $(0.049)$ & $(0.025)$ & $(p=0.001)$ & $(0.049)$ & $(0.025)$ & $(p=0.001)$ \\
\hline Excl. Poland, Korea, Spain, Slovak Rep. & $0.246^{\text {***** }}$ & 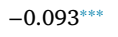 & 8.34 & $0.248^{* * * *}$ & $-0.094^{* * *}$ & 9.04 \\
\hline $\mathrm{N}=20,864$ & $(0.059)$ & $(0.032)$ & $(p=0.004)$ & $(0.057)$ & $(0.031)$ & $(p=0.003)$ \\
\hline Excl. Poland, Germany, and Slovak Rep. & $0.204^{* * *}$ & $-0.078^{* * * *}$ & 7.73 & $0.203^{* * * *}$ & $-0.077^{* * *}$ & 7.61 \\
\hline $\mathrm{N}=21,763$ & $(0.054)$ & $(0.028)$ & $(p=0.005)$ & $(0.054)$ & $(0.028)$ & $(p=0.006)$ \\
\hline Employees in age $20-64$ & $0.215^{* * * *}$ & $-0.079^{* * * *}$ & 11.2 & $0.213^{\text {**** }}$ & $-0.078^{* * *}$ & 10.8 \\
\hline $\mathrm{N}=25,618$ & $(0.047)$ & $(0.024)$ & $(p=0.000)$ & $(0.048)$ & $(0.024)$ & $(p=0.001)$ \\
\hline Employees in age $25-64$ & $0.176^{\text {****** }}$ & $-0.043^{* *}$ & 5.27 & $0.171^{\text {**** }}$ & $-0.042^{* *}$ & 4.90 \\
\hline $\mathrm{N}=23,780$ & $(0.059)$ & $(0.021)$ & $(p=0.022)$ & $(0.046)$ & $(0.021)$ & $(p=0.027)$ \\
\hline Employees in age $25-54$ & $0.210^{* * * *}$ & $-0.075^{* * * *}$ & 10.4 & $0.204^{* * * *}$ & $-0.071^{* * *}$ & 9.52 \\
\hline $\mathrm{N}=19,791$ & $(0.042)$ & $(0.023)$ & $(p=0.001)$ & $(0.041)$ & $(0.023)$ & $(p=0.002)$ \\
\hline
\end{tabular}

Notes. ${ }^{*} p<0.10,{ }^{* *} p<0.05,{ }^{* * *} p<0.01$. Robust standard errors in parentheses, clustered at the age-group-by-country level. The informal learning dependent variable is standardised. The standardised unemployment rate (at the age-group-by-country level, six years prior to the interview) is used as a selection instrument in the estimations presented in column (1), whereas estimations in column (2) add the interaction of the latter with the corresponding standardised EPL indexes for permanent and temporary employment.

Table A3

Other summary statistics.

\begin{tabular}{|c|c|c|c|c|c|c|c|}
\hline \multirow[t]{2}{*}{ Variable } & \multicolumn{2}{|c|}{ Permanent } & \multicolumn{2}{|c|}{ Temporary } & \multirow{2}{*}{$\begin{array}{l}\text { Diff. } \\
\text { p-value }\end{array}$} & \multicolumn{2}{|l|}{ All } \\
\hline & Mean & Std. Dev. & Mean & Std. Dev. & & Min & $\operatorname{Max}$ \\
\hline \multicolumn{8}{|l|}{ Job-content characteristics } \\
\hline High-skilled occupations & 0.47 & 0.50 & 0.30 & 0.46 & 0.000 & 0 & 1 \\
\hline Task discretion (standardised index) ${ }^{\mathrm{a}}$ & 0.11 & 0.99 & -0.26 & 1.08 & 0.000 & -2.81 & 2.43 \\
\hline Task collaboration and team work (standardised index) ${ }^{\mathrm{a}}$ & 0.06 & 0.92 & 0.09 & 0.99 & 0.096 & -2.69 & 1.05 \\
\hline Problem-solving tasks (standardised index) ${ }^{a}$ & 0.12 & 0.94 & -0.12 & 1.06 & 0.000 & -2.28 & 1.17 \\
\hline Planning tasks (standardised index) ${ }^{\mathrm{a}}$ & 0.06 & 1.02 & -0.14 & 0.95 & 0.000 & -2.74 & 3.82 \\
\hline Physical tasks (standardised) & 0.01 & 0.98 & 0.35 & 0.95 & 0.000 & -1.09 & 1.13 \\
\hline Numeracy-related tasks (standardised index) & 0.16 & 0.98 & -0.18 & 1.05 & 0.000 & -1.68 & 3.55 \\
\hline Literacy-related tasks (standardised index) & 0.11 & 0.94 & -0.33 & 1.17 & 0.000 & -2.82 & 4.29 \\
\hline ICT-related tasks (standardised index) & 0.07 & 1.01 & -0.37 & 1.04 & 0.000 & -1.37 & 2.71 \\
\hline \multicolumn{8}{|l|}{ Other characteristics } \\
\hline Job satisfaction & 0.01 & 0.98 & -0.19 & 1.04 & 0.000 & -3.63 & 1.18 \\
\hline Learning motivation & -0.12 & 0.98 & -0.06 & 1.07 & 0.085 & -3.32 & 1.24 \\
\hline Political efficacy perception ${ }^{a}$ & -0.01 & 1.01 & -0.10 & 1.00 & 0.000 & -1.38 & 1.83 \\
\hline Social trust $\mathrm{t}^{\mathrm{a}}$ & -0.03 & 0.97 & -0.22 & 0.88 & 0.000 & -1.41 & 2.60 \\
\hline Health status & -0.01 & 0.98 & -0.02 & 1.01 & 0.860 & -1.50 & 2.59 \\
\hline Observations & 22,795 & 3058 & & 25,853 & & & \\
\hline
\end{tabular}

a Due to lower response rate, we have fewer observations for these variables.

Table A4

MTEs estimates and standard errors.

\begin{tabular}{|c|c|c|c|c|c|c|c|}
\hline U_D 1 & $\begin{array}{l}0.128^{* *} \\
(0.053)\end{array}$ & U_D 30 & $\begin{array}{l}0.241^{* * * *} \\
(0.078)\end{array}$ & U_D 60 & $\begin{array}{l}0.306^{* * *} \\
(0.102)\end{array}$ & U_D 90 & $\begin{array}{l}0.359 * * \\
(0.151)\end{array}$ \\
\hline U_D 10 & $\begin{array}{l}0.192^{\text {**** }} \\
(0.044)\end{array}$ & U_D 40 & $\begin{array}{l}0.269^{* * * *} \\
(0.086)\end{array}$ & U_D 70 & $\begin{array}{l}0.327^{\text {**** }} \\
(0.115)\end{array}$ & U_D 99 & $\begin{array}{l}0.437^{\text {*** }} \\
(0.216)\end{array}$ \\
\hline U_D 20 & $\begin{array}{l}0.220^{* * * * *} \\
(0.056)\end{array}$ & U_D 50 & $\begin{array}{l}0.282^{* * *} \\
(0.098)\end{array}$ & U_D 80 & $\begin{array}{l}0.342^{* *} \\
(0.126)\end{array}$ & & \\
\hline ATE & $\begin{array}{l}0.279^{\text {***** }} \\
(0.096)\end{array}$ & rho1 & $\begin{array}{l}-0.112^{*} \\
(0.048)\end{array}$ & rho0 & $\begin{array}{l}-0.054^{* *} \\
(0.023)\end{array}$ & $\begin{array}{l}\mid \text { rho1| - } \\
\text { |rho0| }\end{array}$ & $\begin{array}{l}0.058^{* * *} \\
(0.026)\end{array}$ \\
\hline
\end{tabular}

Notes. ${ }^{*} p<0.10,{ }^{* *} p<0.05,{ }^{* * *} p<0.01$. Standard errors bootstrapped with 200 replications in parentheses (each replication is a bootstrap sample of clusters at the age-groupby-country level). This table shows the average treatment effects (ATEs) for each percentile of the distribution of U_D, computed at the mean value of all covariates in a FIML specification similar to specification (5) of Table 4 that allows for different correlation parameters $\rho_{1} \neq \rho_{0} . \mathrm{N}=25,853$. 


\section{References}

Acemoglu, D., Pischke, J., 1999. Beyong Becker: training in imperfect labour markets. Econ. J. 109 (453), 112-142.

Angrist, J., Pischke, J., 2009. Mostly Harmless Econometrics: An Empiricist's Companion. Princeton University Press, Princeton.

Arrow, K., 1962. The economic implications of learning-by-doing. Rev. Econ. Stud. 24 (3), 155-173.

Arulampalam, W., Booth, A., 1998. Training and labour market flexibility: is there a trade-off? Br. J. Ind. Relat. 36 (4), 521-536.

Arulampalam, W., Booth, A., Bryan, M., 2004. Training in Europe. J. Eur. Econ. Assoc. 2 (2-3), 346-360.

Atkinson, A., 1998. Exclusion, Employment and Opportunity. CASE Working Paper, Centre for Analysis of Social Exclusion. London School of Economics.

Autor, D., 2001. Why do temporary help firms provide free general skills training? Q. J. Econ. 116 (4), 1409-1448.

Belzil, C., Leonardi, M., 2007. Can risk aversion explain schooling attainments? Evidence from Italy. Labour Econ. 14 (6), 957-970.

Ben-Porath, Y., 1967. The production of human capital and the life cycle of earnings. J. Polit. Econ. 75, 352-365.

Berton, F., Garibaldi, P., 2012. Workers and firms sorting into temporary jobs. Econ. J. 122 (562), 125-154.

Booth, A., 1991. Job-related formal training: who receives it and what is it worth? Oxf. Bull. Econ. Stat. 53 (3), 281-294.

Booth, A., Francesconi, M., Frank, J., 2002. Temporary jobs: stepping stones or dead ends? Econ. J. 112 (480), 189-213.

Bucciol, A., Zarri, L., 2015. The shadow of the past: financial risk taking and negative life events. J. Econ. Psychol. 48, 1-16.

Caliendo, M., Schmidl, R., 2016. Youth unemployment and active labor market policies in Europe. IZA J. Labor Policy 5 (1), 1-30.

Callen, M., Isaqzadeh, M., Long, J., Sprenger, C., 2014. Violence and risk preference: experimental evidence from Afghanistan. Am. Econ. Rev. 104 (1), 123-148.

Cameron, L., Shah, M., 2015. Risk-taking behavior in the wake of natural disasters. J. Hum. Resour. 50 (2), 484-515.

Chuang, Y., Schechter, L., 2015. Stability of experimental and survey measures of risk, time, and social preferences: a review and some new results. J. Dev. Econ. 117, 151-170.

Cockx, B., Picchio, M., 2012. Are short-lived jobs stepping stones to long-lasting jobs? Oxf. Bull. Econ. Stat. 74 (5), 646-675.

Cohn, A., Engelmann, J., Fehr, E., Maréchal, M., 2015. Evidence for countercyclical risk aversion: an experiment with financial professionals. Am. Econ. Rev. 105 (2), 860-885.

Cornelissen, T., Dustmann, C., Raute, A., Schönberg, U., 2016. From LATE to MTE: alternative methods for the evaluation of policy interventions. Labour Econ. 46, 47-60.

Cunha, F., Heckman, J., 2007. The technology of skills formation. Am. Econ. Rev. 97 (2), $31-47$.

Cutulli, G., Guetto, R., 2013. Fixed-term contracts, economic conjuncture, and training opportunities: a comparative analysis across European labour markets. Eur. Sociol. Rev. 29 (3), 616-629.

Destré, G, Lévy-Garboua, L, Sollogoub, M., 2008. Learning from experience or learning from others? Inferring informal training from a human capital earnings function with matched employer-employee data. J. Socio-Econ. 37, 919-938.

De Graaf-Zijl, M., van den Berg, G., Heyma, A., 2011. Stepping stones for the unemployed: the effect of temporary jobs on the duration until (regular) work. J. Popul. Econ. 24 (1), 107-139.

De Grip, A., 2008. Economic perspectives of workplace learning. In: Nijhof, W., Nieuwenhuis, L. (Eds.), The Learning Potential of the Workplace. Sense Publishers, Rotterdam, Netherlands, pp. 15-29.

De Grip, A., Sauermann, J., Sieben, I., 2016. The role of peers in estimating tenure-performance profiles: evidence from personnel data. J. Econ. Behav. Organ. 126, 39-54.

De Oliveira, A., Croson, R., Eckel, C., 2012. Are preferences stable across domains? An experimental investigation of social preferences in the field. South. Econ. J. 79 (1), $15-45$.

European Commission, 2010. Employment in Europe 2010. Publications Office of the European Union, Luxembourg.

European Commission, 2007. Towards Common Principles of Flexicurity: More and Better Jobs Through Flexibility and Security. Publications Office of the European Union, Luxembourg.

Faccini, R., 2014. Reassessing labour market reforms: temporary contracts as a screening device. Econ. J. 124 (575), 167-200.

Gagliarducci, S., 2005. The dynamics of repeated temporary jobs. Labour Econ. 12 (4), 429-448.

Gebel, M., 2013. Is a temporary job better than unemployment? A cross-country comparison based on British, German, and Swiss panel data. J. Appl. Soc. Sci. Stud. 133 (2), 143-155.

Guiso, L., Sapienza, P., Zingales, L., 2013. Time varying risk aversion. NBER Working paper Series No. 19284. National Bureau of Economic Research, Massachusetts.

Givord, P., Wilner, L., 2015. When does the stepping-stone work? Fixed-term contracts versus temporary agency work in changing economic conditions. J. Appl. Econometr. 30 (5), 787-805.

Green, F., 1993. The determinants of training of male and female employees in Britain. Oxf. Bull. Econ. Stat. 55 (1), 103-122.

Greene, W., 2012. Econometric Analysis, seventh ed. Pearson Education, New York.

Hardardóttir, H., 2017. Long term stability of time preferences and the role of the macroeconomic situation. J. Econ. Psychol. 60, 21-36.
Heckman, J., 1978. Dummy endogenous variables in a simultaneous equation system. Econometrica 46 (4), 931-959.

Heckman, J., 1976. A life-cycle model of earnings, learning, and consumption. J. Polit. Econ. 84 (4), 11-44.

Heckman, J., Lochner, L., Cossa, R., 2002. Learning-by-Doing Vs. On-The-Job training: Using Variation Induced by the EITC to Distinguish Between Models of Skill Formation. National Bureau of Economic Research, Massachusetts NBER Working paper series No. 9083.

Heckman, J., Navarro-Lozano, S., 2004. Using matching, instrumental variables, and control functions to estimate economic choice models. Rev. Econ. Stat. 86 (1), 30-57.

Heckman, J., Smith, J., 2004. The determinants of participation in a social program: evidence from a prototypical job training program. J. Labor Econ. 22 (2), 243-298.

Heckman, J., Tobias, J., Vytlacil, E., 2001. Four parameters of interest in the evaluation of social programs. Southern Econ. J. 68 (2), 210-223.

Heckman, J., Vytlacil, E., 2005. Structural equations, treatment effects, and econometric policy evaluation. Econometrica 73 (3), 669-738.

Heckman, J., Vytlacil, E., 2001. Policy-relevant treatment effects. Am. Econ. Rev. 91 (2), $107-111$.

Heckman, J., Vytlacil, E., 1999. Local instrumental variables and latent variable models for identifying and bounding treatment effects. Proc. Natl. Acad. Sci. 96, 4730-4734.

Holmlund, B., Storrie, D., 2002. Temporary work in turbulent times: the Swedish experience. Econ. J. 112 (480), 245-269.

ILO, 2010. The impact of the economic and financial crisis on youth employment: measures for labour market recovery in the European Union, Canada and the United States. International Labour Office, Youth Employment Programme Employment Working Paper No. 70. ILO, Geneva.

Imbens, G., Wooldridge, J., 2009. Recent developments in the econometrics of program evaluation. J. Econ. Lit. 47 (1), 5-86.

Jahn, E., Pozzoli, D., 2013. The pay gap of temporary agency workers - Does the temporary sector experience pay off? Labour Econ. 24, 48-57.

Jahn, E., Rosholm, M., 2014. Looking beyond the bridge: the effect of temporary agency employment on labor market outcomes. Eur. Econ. Rev. 65, 108-125.

Kahn, L., 2010. Employment protection reforms, employment and the incidence of temporary jobs in Europe: 1996-2001. Labour Econ. 17, 1-15.

Kirby, J., Knapper, C., Evans, C., Carty, A., Gadula, C., 2003. Approaches to learning at work and workplace climate. Int. J. Train. Dev. 7 (1), 31-52.

Killingsworth, M., 1982. "Learning-by-doing" and "Investment in Training": a synthesis of two "Rival" models of the life cycle. Rev. Econ. Stud. 49 (2), 263-271.

Koopmans, H., Doornbos, A., Eekelen, I., 2006. Learning in interactive work situations: it takes two to tango; why not invite both partners to dance? Hum. Resour. Dev. Q. 17, $135-158$.

Leuven, E., Oosterbeek, H., 2008. An alternative approach to estimate the wage returns to private-sector training. J. Appl. Econometr. 23, 423-434.

Loh, E., 1994. Employment probation as a sorting mechanism. Ind. Labor. Relat. Rev. 47 (3), 471-486.

Maddala, G., 1983. 'Limited-Dependent and Qualitative Variables in Econometrics' (Econometric Society Monographs, 3) (Kindle Locations 5759-5766). Cambridge University Press. Kindle Edition.

Malmendier, U., Nagel, S., 2011. Depression babies: do macroeconomic experiences affect risk taking? Q. J. Econ. 126 (1), 373-416.

Malmendier, U., Nagel, S., 2016. Learning from inflation experiences. Q. J. Econ. 131 (1), 53-87.

Marsick, V., Watkins, K., Callahan, M., Volpe, M., 2009. Informal and incidental learning in the workplace. In: Smith, M., DeFrates-Densch, N. (Eds.), Handbook of Research On Adult Learning and Development. Routledge, New York, NY, pp. 570-599.

Maurer, T., Weiss, E., 2010. Continuous learning skill demands: associations with managerial job content, age, and experience. J. Bus. Psychol. 25 (1), 1-13.

Meier, S., Sprenger, C., 2015. Temporal stability of time preferences. Rev. Econ. Stat. 97 (2), 273-286.

Miranda, A, Rabe-Hesketh, S, 2006. Maximum likelihood estimation of endogenous switching and sample selection models for binary, count, and ordinal variables. Stata J. 6 (3), 285-308.

Mincer, J., 1997. The production of human capital and the lifecycle of earnings: variations on a theme. J. Labor Econ. 15 (1), 26-47.

Mincer, J., 1974. Schooling, Experience and Earnings. Columbia University Press, New York.

Nagypál, E., 2007. Learning by doing vs. learning about match quality: can we tell them apart? Rev. Econ. Stud. 74 (2), 537-566.

O'Connell, P., Byrne, D., 2012. The determinants and effects of training at work: bringing the workplace back in. Eur. Sociol. Rev. 28 (3), 283-300.

OECD, 2014. OECD Employment Outlook 2014. OECD Publishing.

OECD, 2014b. Technical Report of the Survey of Adult Skills, Reader's Companion. OECD Publishing.

OECD, 2013a. Skilled For Life? Key Findings from the Survey of Adult Skills. OECD Publishing.

OECD, 2013b. OECD Employment Outlook 2013. OECD Publishing.

OECD, 2010. Recognition of Non-Formal and Informal Learning: Country Practices. OECD Publishing.

OECD, 2006. OECD Employment Outlook 2006. OECD Publishing.

OECD, 2004. OECD Employment Outlook 2004. OECD Publishing.

Quandt, R., 1972. A new approach to estimating switching regressions. J. Am. Statist. Assoc. 67 (338), 306-310.

Quinones, M., Ford, J., Teachout, M., 1995. The relationship between work experience and job performance: a conceptual and meta-analytic review. Pers. Psychol. 48, 887-910. 
Rabe-Hesketha, S., Skrondalb, A., Picklesc, A., 2005. Maximum likelihood estimation of limited and discrete dependent variable models with nested random effects. J. Econometr. 128, 301-323.

Roodman, D., 2011. Fitting fully observed recursive mixed-process models with cmp. Stata J. 11 (2), 159-206.

Rosen, S., 1972. Learning and experience in the labour market. J. Hum. Resour. 7, 326-342.

Sala, H., Silva, J., Toledo, M., 2012. Flexibility at the margin and labor market volatility in OECD countries. Scand. J. Econ. 114 (3), 991-1017.

Sicherman, N., Galor, O, 1990. A theory of career mobility. J. Polit. Econ. 98 (1), 169-192.

Steijn, B., Need, A., Gesthuizen, M., 2006. Well Begun, Half Done? Long-term effects of labour market entry in the Netherlands 1950-2000. Work, Employ. Soc. 20 (3), $453-472$
Tesluk, P., Jacobs, R., 1998. Toward an integrated model of work experience. Pers. Psychol. 51, 321-355.

Virtanen, M., Kivimäki, M, Joensuu, M., Virtanen, P., Elovainio, M., Vahtera, J., 2005 Temporary employment and health: a review. Int. J. Epidemiol. 34 (3), 610-622.

Wasmer, E., 1999. Competition for jobs in a growing economy and the emergence of dualism. Econ. J. 109 (457), 349-371.

Weiss, Y., 1986. The determination of life cycle earnings: a survey. In: Ashenfelter, O., Layard, R., Card, D. (Eds.), Handbook of Labor Economics. Elsevier 603 Virtanen 640 doi:10.1016/S1573-4463(86)01014-3.

Wooldridge, J., 2010. Econometric Analysis of Cross Section and Panel Data, second edition MIT Press, Cambridge, MA.

Wooldridge, J., 2015. Control function methods in applied econometrics. J. Hum. Resour. 50 (2), 420-445. 